\title{
Wintertime Southern Hemisphere Jet Streams Shaped by Interaction of Transient Eddies with Antarctic Orography $\mathscr{O}$
}

\author{
Matthew Patterson, ${ }^{a}$ Tim Woollings, ${ }^{a}$ Thomas J. Bracegirdle, ${ }^{\mathrm{b}}$ And Neil T. Lewis ${ }^{\mathrm{a}}$ \\ ${ }^{a}$ Atmospheric, Oceanic and Planetary Physics, University of Oxford, Oxford, United Kingdom \\ ${ }^{\mathrm{b}}$ British Antarctic Survey, Cambridge, United Kingdom
}

(Manuscript received 6 March 2020, in final form 7 September 2020)

\begin{abstract}
The wintertime Southern Hemisphere extratropical circulation exhibits considerable zonal asymmetries. We investigate the roles of various surface boundary conditions in shaping the mean state using a semi-realistic, atmosphereonly climate model. We find, in agreement with previous literature, that tropical sea surface temperature (SST) patterns are an important contributor to the mean state, while midlatitude SSTs and sea ice extent play a smaller role. Our main finding is that Antarctic orography has a first-order effect on the structure of the midlatitude circulation. In the absence of Antarctic orography, equatorward eddy momentum fluxes associated with the orography are removed and hence convergence of eddy momentum in midlatitudes is reduced. This weakens the Indian Ocean jet, making Rossby wave propagation downstream to the South Pacific less favorable. Consequently, the flow stagnates over the mid- to high-latitude South Pacific and the characteristic split jet pattern is destroyed. Removing Antarctic orography also results in a substantial warming over East Antarctica partly because transient eddies are able to penetrate farther poleward, enhancing poleward heat transport. However, experiments in which a high-latitude cooling is applied indicate that these temperature changes are not the primary driver of circulation changes in the midlatitudes. Instead, we invoke a simple barotropic mechanism in which the orographic slope creates an effective potential vorticity gradient that alters the eddy momentum flux.
\end{abstract}

KEYWORDS: Antarctica; Southern Hemisphere; Atmospheric circulation; Rossby waves; Jets; Primitive equations model

\section{Introduction}

Many of the key zonal mean features of Earth's atmospheric circulation, such as eddy-driven jets and Hadley cells, can be understood under zonally symmetric surface boundary conditions. Time-mean zonal asymmetries to the atmospheric flow can then largely be explained by the addition of zonally varying sea surface temperatures (SSTs), land-sea contrasts, and orography (e.g., Wang and Ting 1999; Held et al. 2002; Brayshaw et al. 2009, 2011). The atmospheric circulation of the Southern Hemisphere (SH) during winter is notably asymmetric and characterized by an upper-level jet spiraling in toward Antarctica (Hoskins and Hodges 2005; Williams et al. 2007). This can be seen in Fig. 1, plotted using austral winter [June-August (JJA)] ERA-Interim reanalysis data for the years 1979-2014. A strong midlatitude jet exists over the Indian Ocean, which subsequently bifurcates into subtropical and polar branches, forming the so-called split jet over the South Pacific (e.g., van Loon et al. 1972; Karoly and Vincent 1998; Bals-Elsholz et al. 2001). This behavior contrasts strongly with the summer season, in which the atmospheric circulation is largely zonally symmetric.

Inatsu and Hoskins (2004) performed a set of atmosphereonly general circulation model (AGCM) experiments, in which

Supplemental information related to this paper is available at the Journals Online website: https://doi.org/10.1175/JCLI-D-200153.s1.

Corresponding author: Matthew Patterson, matthew.patterson@ physics.ox.ac.uk they removed various aspects of the surface boundary conditions that may contribute to the structure of the $\mathrm{SH}$ winter storm tracks. In particular, they removed orography from southern Africa and South America and set SSTs to the zonal mean in the tropics and midlatitudes. They concluded that zonal asymmetries in tropical SSTs were responsible for most of the large-scale structure in midlatitudes. They suggested that convection related to the Asian monsoon triggers a stationary Rossby wave that propagates southeast toward the South Pacific, creating the split in the flow.

A distinct but complementary perspective on the split jet centers around the strengthening of the subtropical jet in late spring (Williams et al. 2007; Nakamura and Shimpo 2004). The subtropical jet is driven by angular momentum transport via the Hadley cell and acts as a strong waveguide for midlatitude eddies, suppressing the eddy-mean flow feedback of the poleward eddy-driven jet (Nakamura and Shimpo 2004). That is, upper-level eddies forming upstream over the Indian Ocean become trapped by the subtropical jet and are separated in latitude from the region of maximum baroclinicity at the surface (Nakamura and Sampe 2002). The upper-level eddies are unable to interact with the surface baroclinic zone, suppressing wave activity and hence reducing the number of meridionally propagating eddies that provide the momentum source for the eddy-driven jet. However, sufficient upper-level eddy activity persists at high latitudes to maintain a weak polar jet and hence a split jet is observed.

On the other hand, Ogawa et al. (2016) emphasized the importance of the midlatitude SST front location in maintaining the split jet. The SST front determines the region of maximum baroclinicity and thus is the source region of transient 

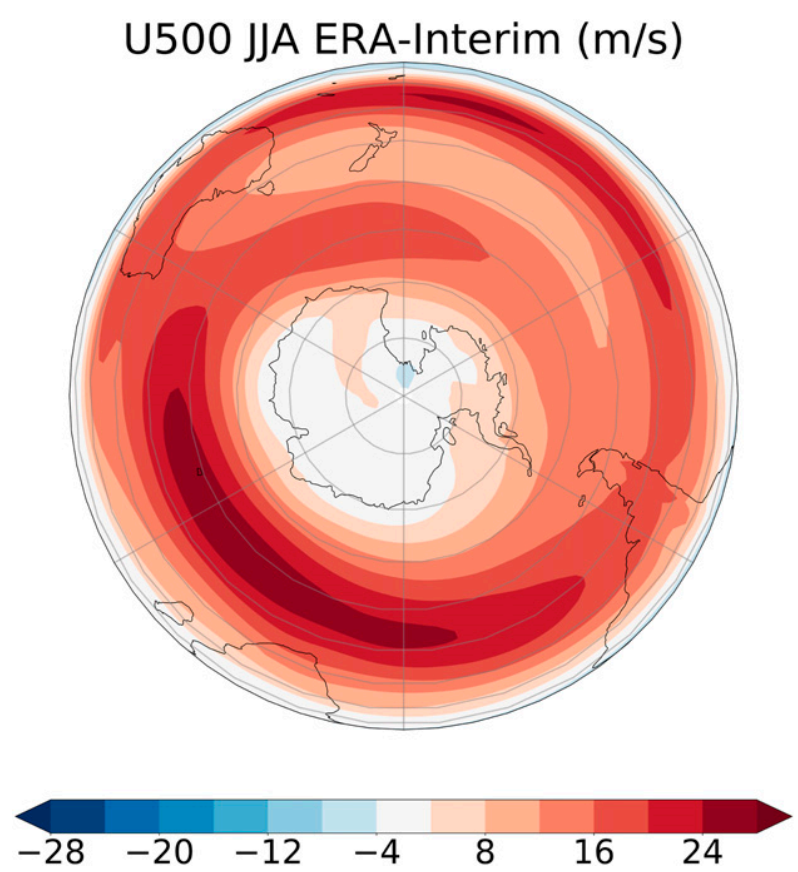

FIG. 1. ERA-Interim mean zonal wind on the 500-hPa level for the SH during JJA.

eddies, which provide the momentum driving the eddy-driven jet. They argued that a split jet forms over the South Pacific because there is sufficient separation in latitude between the midlatitude SST front $\left(\sim 55^{\circ} \mathrm{S}\right)$ and the subtropical jet for a poleward eddy-driven jet to form. This contrasts with the Indian Ocean as the SST front formed by the Agulhas Current is located farther equatorward $\left(\sim 40^{\circ} \mathrm{S}\right)$ and there is no splitting of the atmospheric flow.

Additionally, a significant perturbation to the SH circulation is provided by Antarctica. The year-round presence of snow and ice keeps the air above cold, maintaining a strong equatorto-pole temperature contrast. Moreover, much of the Antarctic continent is covered with over $3 \mathrm{~km}$ of ice and the presence of this orography enhances longwave cooling to space (Ogura and Abe-Ouchi 2001; Singh et al. 2016), further cooling the surface. Longwave cooling at the top of the Antarctic Plateau drives a strong and relatively persistent drainage flow that is sharply constrained by topography (Parish and Bromwich 2007). The drainage flow is fed by a meridional overturning circulation that rises between $60^{\circ}$ and $70^{\circ} \mathrm{S}$, moves poleward at upper levels, and subsides over the continent (Parish and Bromwich 2007). While the overturning circulation is thermally direct, eddy fluxes of momentum and heat are necessary to maintain the balance with the easterly Coriolis torque (Juckes et al. 1994).

Several studies have examined the effect of removing Antarctic orography on high-latitude climate. Some consistent findings have included an increase in poleward heat flux (Mechoso 1980, 1981; Parish and Bromwich 2007; Quintanar and Mechoso 1995; Walsh et al. 2000; Ogura and Abe-Ouchi 2001; Singh et al. 2016), an increase in poleward momentum flux (Egger 1991; Parish et al. 1994; Singh et al. 2016), and a reduction in high-latitude cyclogenesis (Mechoso 1980; Simmonds and Law 1995; Walsh et al. 2000). Additionally, Lachlan-Cope et al. (2001) noted that the Antarctic Plateau is displaced by over $10^{\circ}$ from the South Pole, resulting in a significant nonaxisymmetric perturbation to the flow. Using AGCM experiments they found that the displacement of the orography is responsible for the existence of the Amundsen Sea low, a highly variable region of sea level pressure near the West Antarctic coastline. It is clear that Antarctic orography influences the circulation at high latitudes, but how much of a role does it play in shaping the flow in the midlatitudes?

In this study we build on the work of Inatsu and Hoskins (2004) and investigate the influence that altering various surface boundary conditions has on the zonally asymmetric structure of the $\mathrm{SH}$ wintertime circulation. We particularly consider the importance of Antarctic orography for the configuration of jet streams and demonstrate that without the plateau, the split jet does not form over the South Pacific.

In section 2 the model and experiments are described followed by a comparison of the CONTROL experiment with ERAInterim reanalysis in section 3 . The circulation in each of the model runs is then discussed in section 4 before going into more depth on the role of Antarctic orography in section 5. Subsequently, in section 6 a barotropic model is employed to explain some of the effects of orography on circulation and conclusions are given in section 7 .

\section{Data and methodology}

a. Isca

For this study we perform a set of idealized AGCM experiments using the modeling framework Isca (Vallis et al. 2018). Our CONTROL experiment is broadly similar to the setup used by Thomson and Vallis (2018) except we use prescribed SSTs rather than a slab ocean. The model integrates the primitive equations using a spectral dynamical core with 40 levels in the vertical and at T42 horizontal resolution. This translates to a grid point spacing of approximately $2.8^{\circ}$ at the equator.

Water vapor is represented in the model atmosphere; its interactions with the atmosphere and surface by means of latent heating effects are included, and it is advected with the flow. Evaporation of water vapor occurs at the surface and is parameterized as in Frierson et al. (2006) and Thomson and Vallis (2018). Here, the evaporative resistance parameter is given a value of 1.0 over the land and 0.7 for the sea surface, following Thomson and Vallis (2018). The "fast" condensation of water vapor, whereby water vapor is removed as precipitation that reaches the surface immediately, occurs aloft. This treatment of condensation means that there is no explicit liquid water content in the model atmosphere, and thus by extension, no representation of clouds (Vallis et al. 2018). Precipitation may occur due to large-scale condensation within a grid box, or moist convection. Large-scale condensation is parameterized following Frierson et al. (2006), and moist convective adjustment is parameterized following Betts and Miller (1986).

Radiative transfer is represented using the RRTM multiband radiation scheme (Clough et al. 2005). Water vapor in the 

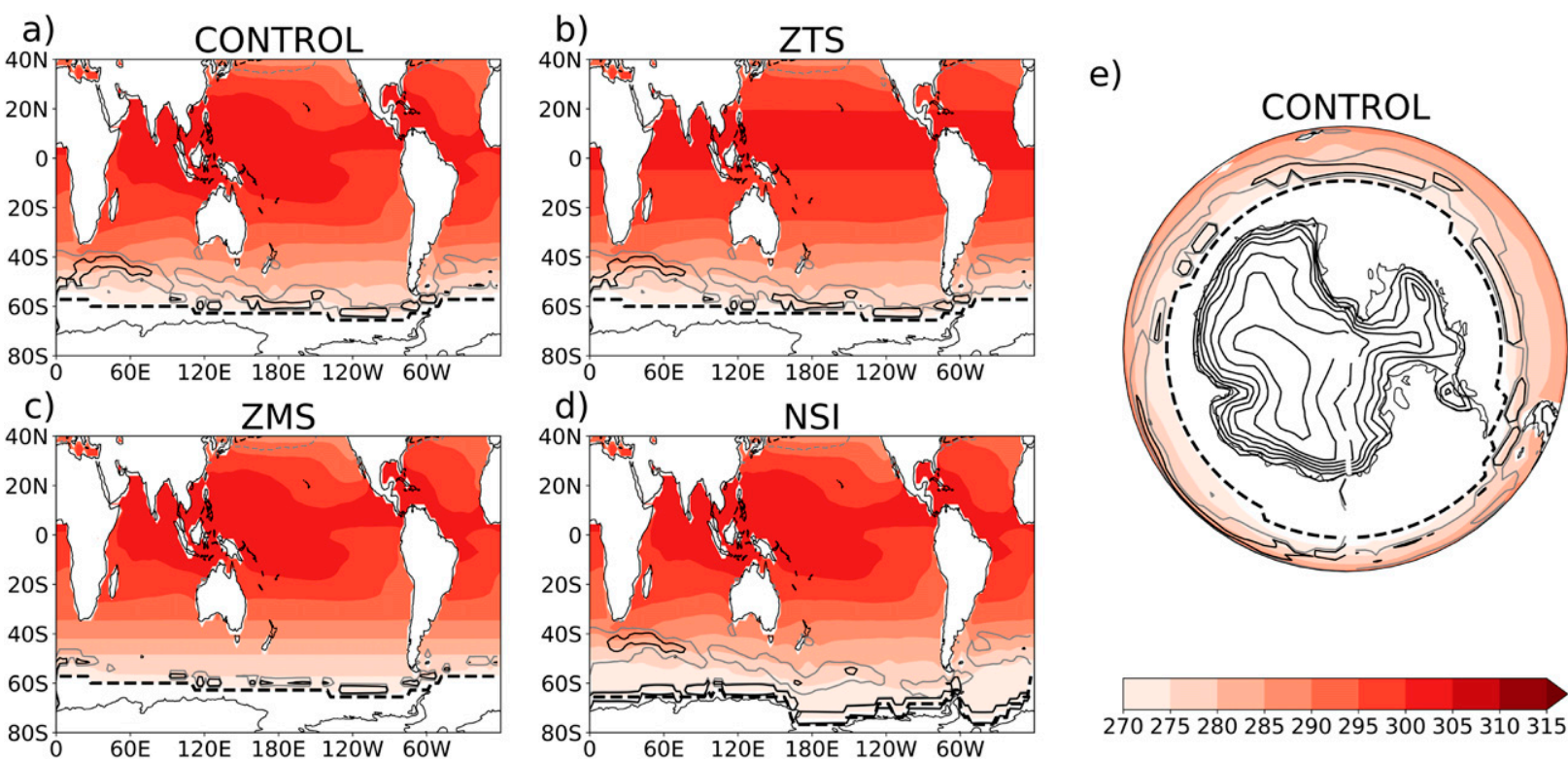

FIG. 2. A comparison of boundary conditions used in experiments. JJA SSTs are shown by colors for the (a) CONTROL, (b) ZTS, (c) ZMS, and (d) NSI runs, alongside the $50 \%$ sea ice edge indicated by a dashed black line. Meridional SST gradients above $5 \times 10^{-7}$ and $8 \times 10^{-7} \mathrm{~K} \mathrm{~m}^{-1}$ are indicated by solid gray and black curves, respectively. (e) Topography over Antarctica in the CONTROL run with contours drawn every $500 \mathrm{~m}$ starting at $500 \mathrm{~m}$.

model atmosphere is radiatively active at long and short wavelengths. The carbon dioxide concentration is kept fixed at 350 ppmv, and the zonal mean ozone concentration is set at 1990 levels. Surface albedo values are set to 0.25 for ocean, 0.325 for land, and 0.7 for ice, following Thomson and Vallis (2018). These choices account for the absence of a cloud albedo contribution and yield a planetary albedo of 0.31 , which is comparable to the value of 0.29 calculated for the real Earth system (Stephens et al. 2015). The effect of ice on the atmosphere is primarily distinguished from that of land and SSTs by its higher albedo.

To include the effect of gravity wave drag on the upper stratosphere, Rayleigh damping with a time scale of 0.5 days is applied in a sponge layer above $1.5 \mathrm{hPa}$, similar to Polvani and Kushner (2002) and Jucker and Gerber (2017). However, subgrid orographic effects and orographic gravity wave drag are excluded from the model. The boundary layer is represented via a Monin-Obukhov scheme (Frierson et al. 2006) with the surface roughness parameter an order of magnitude higher over land [values again follow Thomson and Vallis (2018)].

In terms of surface boundary conditions, the same SSTs and ice fraction as used for AMIP (Taylor et al. 2000) are averaged for each month of the year to produce a monthly varying climatology, which is then used to force the model. Any grid box with an ice fraction of $50 \%$ or greater has its albedo set to the ice albedo value (0.7). The low horizontal resolution means that the model will not fully capture sharp SST gradients (Brayshaw et al. 2008; Sampe et al. 2010). However as we will show, the model is able to represent the key features of the $\mathrm{SH}$ circulation relatively well and SST perturbations in our experiments are large and hence should be easily captured by the model atmosphere. Finally, the land mask and topographic height field are both taken from ERA-Interim (Dee et al. 2011).

\section{b. Model experiments}

Following Inatsu and Hoskins (2004) we alter various boundary conditions and examine the impact of these changes on the atmospheric circulation. An obvious caveat is that the real atmosphere is coupled with the ocean, so in the real Earth system many of the changes imposed here may be mitigated by changes to ocean circulation. Indeed, Singh et al. (2016) emphasized that including an ocean model reduces the change in atmospheric energy transport upon flattening Antarctica, with the largest reduction occurring in the tropics (their Fig. 4). However, our focus is on the mid- to high latitudes where the change is less significant. Imposing different boundary conditions at the surface also allows us to draw more conclusions about the causality of changes in the model.

A CONTROL experiment is integrated for 30 model years with the first two years taken as spinup. As in Inatsu and Hoskins (2004), we perform a run with SSTs between $20^{\circ} \mathrm{N}$ and $20^{\circ} \mathrm{S}$ set to the zonal mean and a run with SSTs south of $35^{\circ} \mathrm{S}$ set to the zonal mean. These are respectively labeled ZTS and ZMS. The SST patterns for both of these runs are shown in Fig. 2, along with the region of high SST gradients. It is clear that in the ZMS run, the midlatitude SST gradients are substantially diminished. To test the sensitivity of the jet latitude to the latitude of the sea ice edge, we retreat the sea ice edge back to the edge of the landmass, calling this run NSI (Fig. 2d). In regions where sea ice is removed, the SSTs are taken to be $273 \mathrm{~K}$. Finally, to test the role of Antarctic orography in $\mathrm{SH}$ circulation, we run the model with Antarctic orography 
TABLE 1. A summary of the boundary conditions used for all experiments.

\begin{tabular}{lll}
\hline \multicolumn{1}{c}{ Experiment } & \multicolumn{1}{c}{ SSTs and sea ice } & Land and orography \\
\hline CONTROL & $\begin{array}{c}\text { Seasonally varying climatology, taken } \\
\text { from AMIP (Taylor et al. 2000) } \\
\text { ZTS }\end{array}$ & $\begin{array}{c}\text { As in ERA-Interim } \\
\text { smooth transition to } 35^{\circ} \mathrm{N} / \mathrm{S}\end{array}$ \\
ZMS & $\begin{array}{l}\text { SSTs south of } 35^{\circ} \mathrm{S} \text { set to zonal mean with } \\
\text { a smooth transition } 20^{\circ} \mathrm{S}-35^{\circ} \mathrm{S} \\
\text { Sea ice edge moved back to the edge } \\
\text { of land }\end{array}$ & As in CONTROL \\
NSI & $\begin{array}{l}\text { As in CONTROL } \\
\text { As in ZTS } \\
\text { As in CONTROL }\end{array}$ & As in CONTROL \\
ZTS_NOROG & Antarctic orography removed \\
COOL & Antarctic orography removed \\
\end{tabular}

removed. Figure 2e shows the CONTROL orography contoured every $500 \mathrm{~m}$. The height and steepness of surface elevation are most significant over East Antarctica where it rises steeply from the coast to over $3000 \mathrm{~m}$ above sea level. We create two runs without Antarctic orography, the first with SSTs as in the CONTROL (NOROG) and the second with the same SSTs as in the ZTS run (NOROG_ZTS). A summary of the model boundary conditions for each run is given in Table 1 .

\section{Comparison of the CONTROL run with ERA-Interim reanalysis}

The experiments that we perform are idealized, however we still require that the model CONTROL run represents the atmosphere sufficiently well for our results to map onto the real Earth system. Figure 3 shows a comparison of the JJA zonal mean temperature and zonal mean zonal wind between the CONTROL run and ERA-Interim. Much like coupled climate models in CMIP5 (Taylor et al. 2012), the model extratropical troposphere is cold biased and the jet is overly equatorward (Bracegirdle et al. 2013; Simpson et al. 2014; Lee 2015). The temperature bias has a magnitude of around $1-2 \mathrm{~K}$ in most of the troposphere but is substantially higher in the lower stratosphere, reaching $9 \mathrm{~K}$. It is likely that the lack of gravity wave drag in the model's lower stratosphere contributes to these biases (e.g., McFarlane 1987). With respect to the zonal wind structure, the midlatitude jet over the Indian Ocean is too strong and equatorward, while the polar front jet over the South Pacific is too weak, the latter being a result found in many CMIP5 models (Bracegirdle et al. 2013; Arakelian and Codron 2012; Patterson et al. 2019). However, the model is here being used for a rather idealized study and we conclude that it represents the SH circulation well enough for our purposes.

\section{Tropical SST asymmetries and stationary Rossby waves}

The key result of Inatsu and Hoskins (2004) was that the observed stationary wave pattern and much of the zonally asymmetric structure to the $\mathrm{SH}$ winter circulation is forced by tropical SST asymmetries. To show that this is reproduced in our experiments, we now plot the $300-\mathrm{hPa}$ stationary eddy streamfunction $\psi^{*}$, calculated as the zonally asymmetric component of the streamfunction, along with wave activity flux vectors $W$ (Takaya and Nakamura 1997, 2001) in Fig. 4. The horizontal components of wave activity flux are calculated as follows:

$$
W=\frac{p}{p_{0}}\left[\begin{array}{l}
\frac{\partial \overline{\psi^{*}}}{\partial x} \frac{\partial \overline{\psi^{*}}}{\partial x}-\overline{\psi^{*}} \frac{\partial^{2} \overline{\psi^{*}}}{\partial x^{2}} \\
\frac{\partial \overline{\psi^{*}}}{\partial x} \frac{\partial \overline{\psi^{*}}}{\partial y}-\overline{\psi^{*}} \frac{\partial^{2} \overline{\psi^{*}}}{\partial x \partial y}
\end{array}\right],
$$

in which $p$ is the pressure level, $p_{0}$ is the surface pressure, and overbars indicate the time mean. We use monthly mean data for this plot to isolate the stationary wave activity flux. The CONTROL run (Fig. 4a) is dominated by zonal wavenumber-1 waves with wave activity propagating southeastward from the Indian Ocean and refracting equatorward to the east of the date line. A comparison of the stationary wave patterns in CONTROL with ERA-Interim is shown in Fig. S1 in the online supplemental material. The patterns are similar, though the stationary wave has a slightly higher amplitude in CONTROL than in reanalysis and the wave activity vectors to the south of Australia are oriented to the southeast rather than eastward. In most of the runs this pattern of wave propagation remains largely the same as in CONTROL; however, in agreement with Inatsu and Hoskins (2004) and Quintanar and Mechoso (1995), the stationary wave pattern and wave activity flux is severely diminished in the runs with zonally symmetric SSTs in the tropics (Figs. 4b,c). The stationary waves are more subtly modified by the removal of Antarctic orography (Fig. 4d) as the pattern of cyclonic and anticyclonic anomalies remains broadly the same, but the center of action over the Indian Ocean is diminished and the wave activity flux is weakened. The Antarctic Plateau clearly does exert some influence on stationary wave propagation as the pattern of wave activity flux found in ZTS (Fig. 4b) is much weaker in ZTS_NOROG (Fig. 4c).

Figure 5 shows the $500-\mathrm{hPa}$ wind and provides a complementary picture to the stationary wave changes in Fig. 4. In spite of the changes to surface temperature gradients and thus local baroclinicity in the ZMS experiment (Fig. 5e), the circulation is relatively unchanged. This appears to contradict the results of Ogawa et al. (2016), who found considerable 

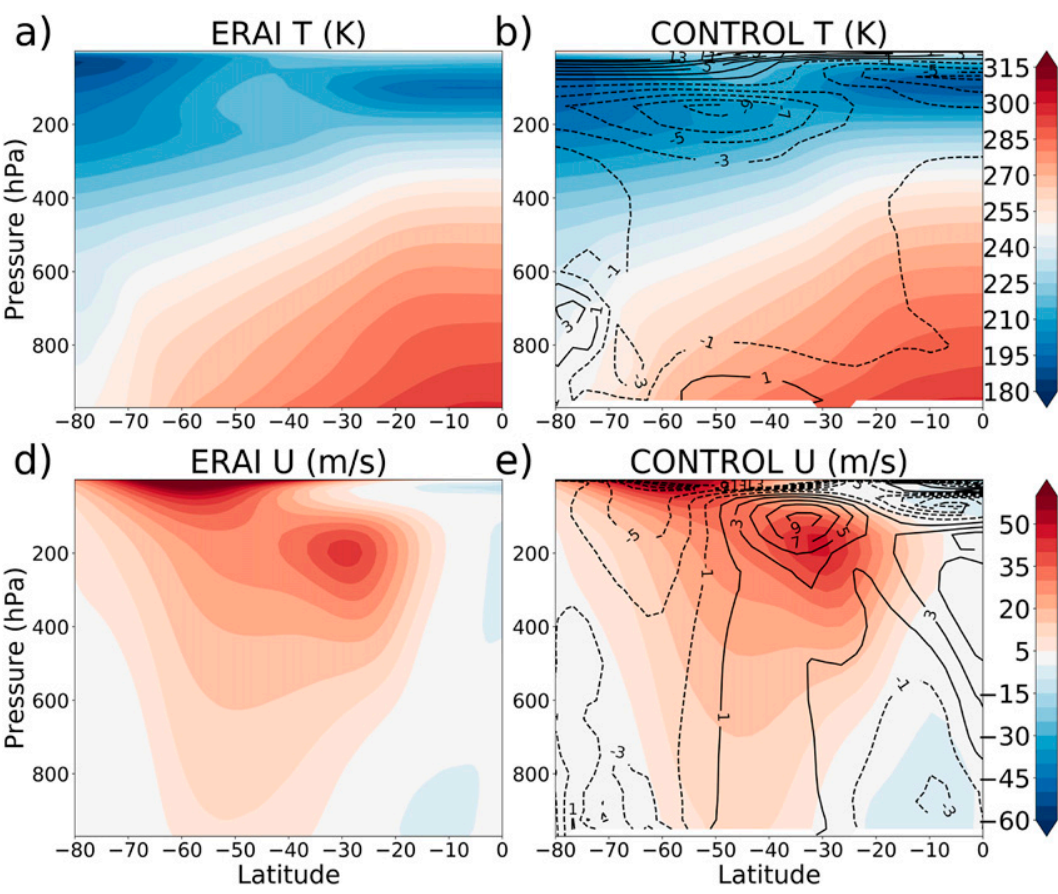

c)

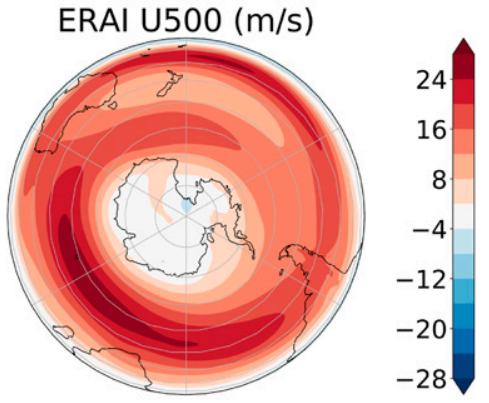

f)

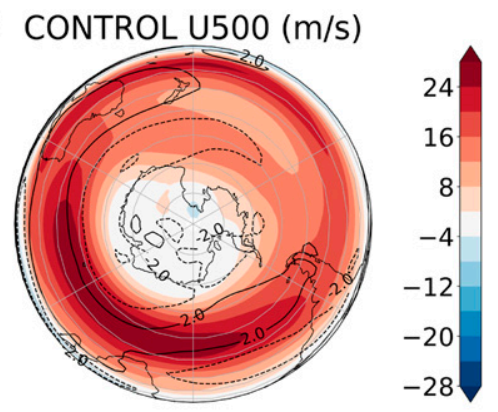

FIG. 3. Comparison of wintertime (JJA) zonal wind and temperature in the CONTROL run with ERA-Interim (1979-2014). Zonal mean temperature is shown by colors for (a) ERA-Interim and (b) CONTROL with contours in (b) indicating the model bias, CONTROL - ERA-Interim (contour interval $2 \mathrm{~K}$, beginning at $\pm 1 \mathrm{~K}$ ). (d), (e) As in (a) and (b), respectively, but for zonal mean zonal wind (bias contour interval of $2 \mathrm{~m} \mathrm{~s}^{-1}$, beginning at $\pm 1 \mathrm{~m} \mathrm{~s}^{-1}$ ). The 500-hPa zonal wind is shown for (c) ERA-Interim and (f) CONTROL with contours again showing the bias (contour interval $2 \mathrm{~m} \mathrm{~s}^{-1}$ ).

differences between runs with and without strong SST gradients. However a key difference lies in the fact that Ogawa et al. (2016) modified SST gradients by changing the meridional structure of the zonal mean SST (see their Fig. 1), whereas in our experiments the zonal mean SST is preserved. In the latter case, the zonal mean temperature profile will be largely the same as in the CONTROL state; however, in the former case this will change, altering the zonal mean winds in line with thermal-wind balance. Hence, it may be that some of the changes observed by Ogawa et al. (2016) relate more to the change in equator-to-pole temperature gradient than to local SST gradients. The NSI run (Fig. 5f) shows a slight weakening of the eddy-driven jet in the southeast Pacific, off the Antarctic peninsula. It is notable that the South Pacific jet in CONTROL is located at high latitudes where it may be affected by removal of the proximal sea ice edge. Plotting Fig. 5 with a higher contour interval also shows wind anomalies in the NSI run of about $-2 \mathrm{~ms}^{-1}$ at all longitudes over the high-latitude Southern Ocean (not shown). A change of this magnitude is similar to that found in other studies on the atmospheric impact of Antarctic sea ice loss (England et al. 2018; Ayres and Screen 2019). Given the current rate of warming, significant Antarctic sea ice reductions are to be expected by the end of this century, with substantial effects on the climate system (Collins et al. 2013). However, in this study we are concerned with the boundary conditions shaping the mean state and it is clear from this figure that flattening Antarctica and removing tropical SST asymmetries have a much larger impact on SH circulation than sea ice retreat, even if these changes are impossible on a human time scale.

As expected, the circulation in the ZTS run is much more zonally symmetric than CONTROL, with the subtropical jet no longer a distinct feature and hence the South Pacific split jet pattern is destroyed (Fig. 5b). However, the split jet pattern is also absent in the NOROG experiment, but for a different reason, as the high-latitude winds over the South Pacific are severely weakened and the subtropical jet is enhanced (Fig. 5d). Over the South Pacific, the anomalies seen in these two runs with respect to CONTROL are almost equal and opposite, although both runs show a weakening over the Indian Ocean. Close examination of zonal wind changes in the ZTS_ NOROG run (Fig. 5c) reveals that the responses to removal of tropical SST asymmetries and flattening Antarctica do not add linearly over the high-latitude South Pacific. That is, taken individually, removing tropical SST asymmetries and flattening Antarctica are both associated with a reduction in the strength of high-latitude westerlies over the South Pacific (Figs. 5b,d), but this is not the case in ZTS_NOROG (Fig. 5c). This nonlinearity can also be seen in Fig. S2f in the online supplemental material, in which anomalies are plotted with respect to ZTS_ NOROG. Note that this study does not assume linearity; rather, we are demonstrating that the observed structure is contingent upon certain key boundary conditions. Another way in which to view the nonlinear behavior is to say that removal of Antarctic orography has a larger impact on atmospheric circulation in the presence of a stationary wave induced 

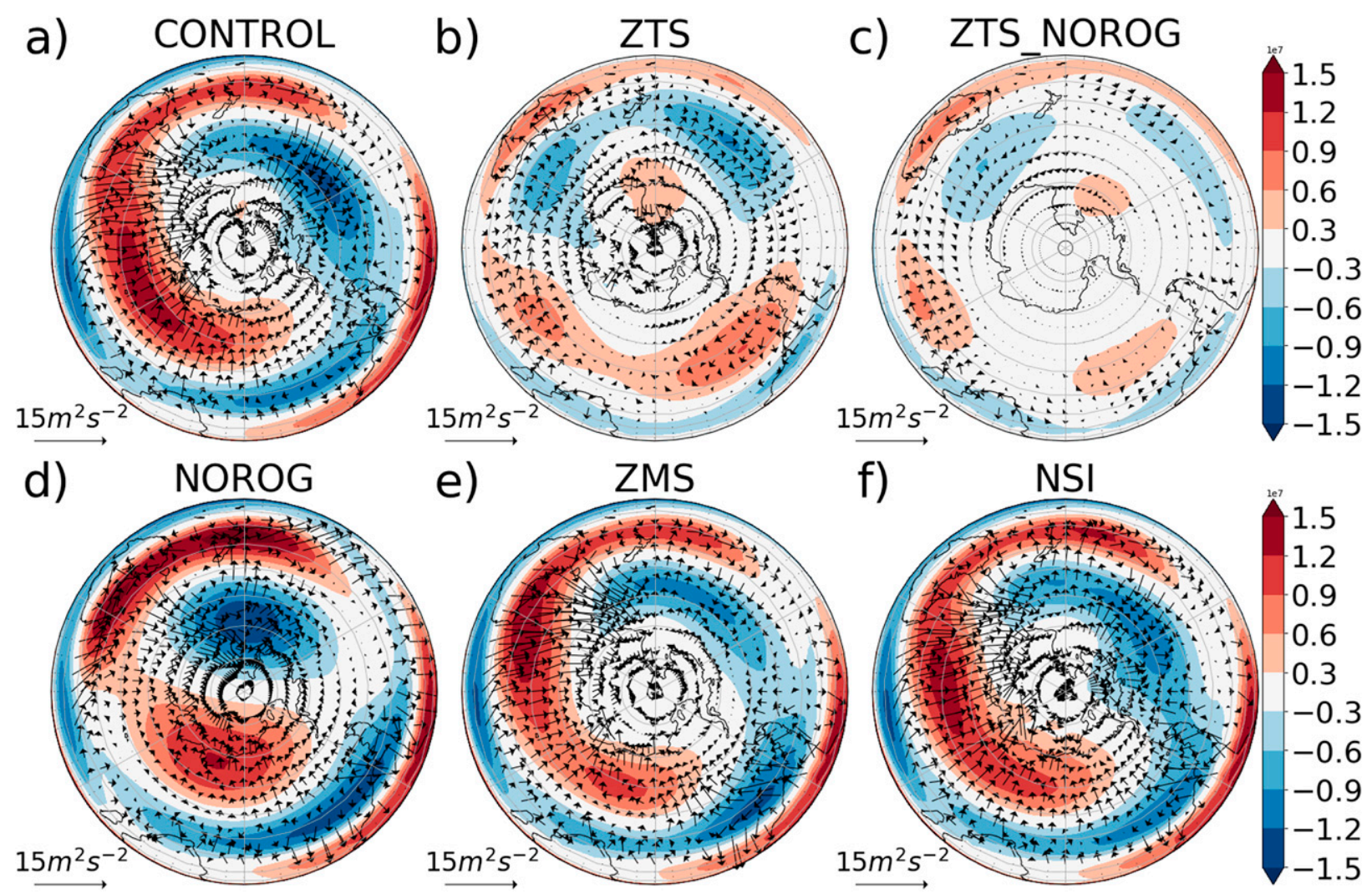

FIG. 4. Time-mean stationary waves for the different model runs during JJA. Each panel shows the 300-hPa stationary eddy streamfunction in colors with contour interval $0.3 \times 10^{-7} \mathrm{~m}^{2} \mathrm{~s}^{-1}$ alongside wave activity flux vectors on the same level. Red and blue colors indicate anomalously cyclonic and anticyclonic flow, respectively.

by tropical SSTs. Regarding the cause of nonlinearity, this requires either nonlinear interaction between stationary wave patterns induced by tropical and high-latitude sources or that transient eddy momentum fluxes play an important role. Seeing that the ZMS and NSI runs do not differ as markedly from the CONTROL run and the role of tropical SST asymmetry has been extensively discussed elsewhere (e.g., Inatsu and Hoskins 2004, 2006), we now focus our attention on the runs without Antarctic orography.

\section{Effects of removing Antarctic orography}

\section{a. Effect on temperature}

Previous studies on the effect of removing Antarctic orography have shown that the surface and air temperatures at high latitudes increase when the plateau is removed (Ogura and Abe-Ouchi 2001; Singh et al. 2016). Figure 6a, which shows the temperature difference between the NOROG and CONTROL runs, illustrates this point. The largest changes to the zonal mean temperature occur below $500 \mathrm{hPa}$ (Fig. 6a). However, it is clear from Fig. $6 c$ that there is a substantial zonal asymmetry to these temperature changes, with increases in $500-\mathrm{hPa}$ temperature of $6 \mathrm{~K}$ over parts of East Antarctica and no significant change over West Antarctica. These regionally varying changes closely correspond with the changes to elevation between the NOROG and CONTROL runs (Fig. 2).

The temperature changes occur for two reasons. First, in the absence of orography, the column of air is deepened and hence there is more mass to absorb longwave radiation from the surface. This in turn heats the atmosphere, which re-emits and warms the surface. Second, the removal of the plateau allows transient eddies, which would normally be confined to the coastline, to access the continent and hence transport heat from lower latitudes, balancing the enhanced loss of energy to space. It therefore appears that there are two main ways in which removal of the Antarctic Plateau could alter the circulation, namely effects relating directly to the removal of the orography and effects through changes to the temperature gradients at high southern latitudes.

To try and understand which of these effects is more important in explaining the circulation changes seen in Figs. $4 \mathrm{e}$ and 5e, we perform a run without the Antarctic orography, but imposing a cooling tendency at high latitudes. This cooling is designed to cancel the temperature effects of removing the plateau. The cooling tendencies are calculated first by performing a run like NOROG, but with Newtonian relaxation of the temperature field south of $65^{\circ} \mathrm{S}$ at all pressure levels, to a seasonally varying climatology calculated from CONTROL. For regions in the CONTROL run which are masked out by 

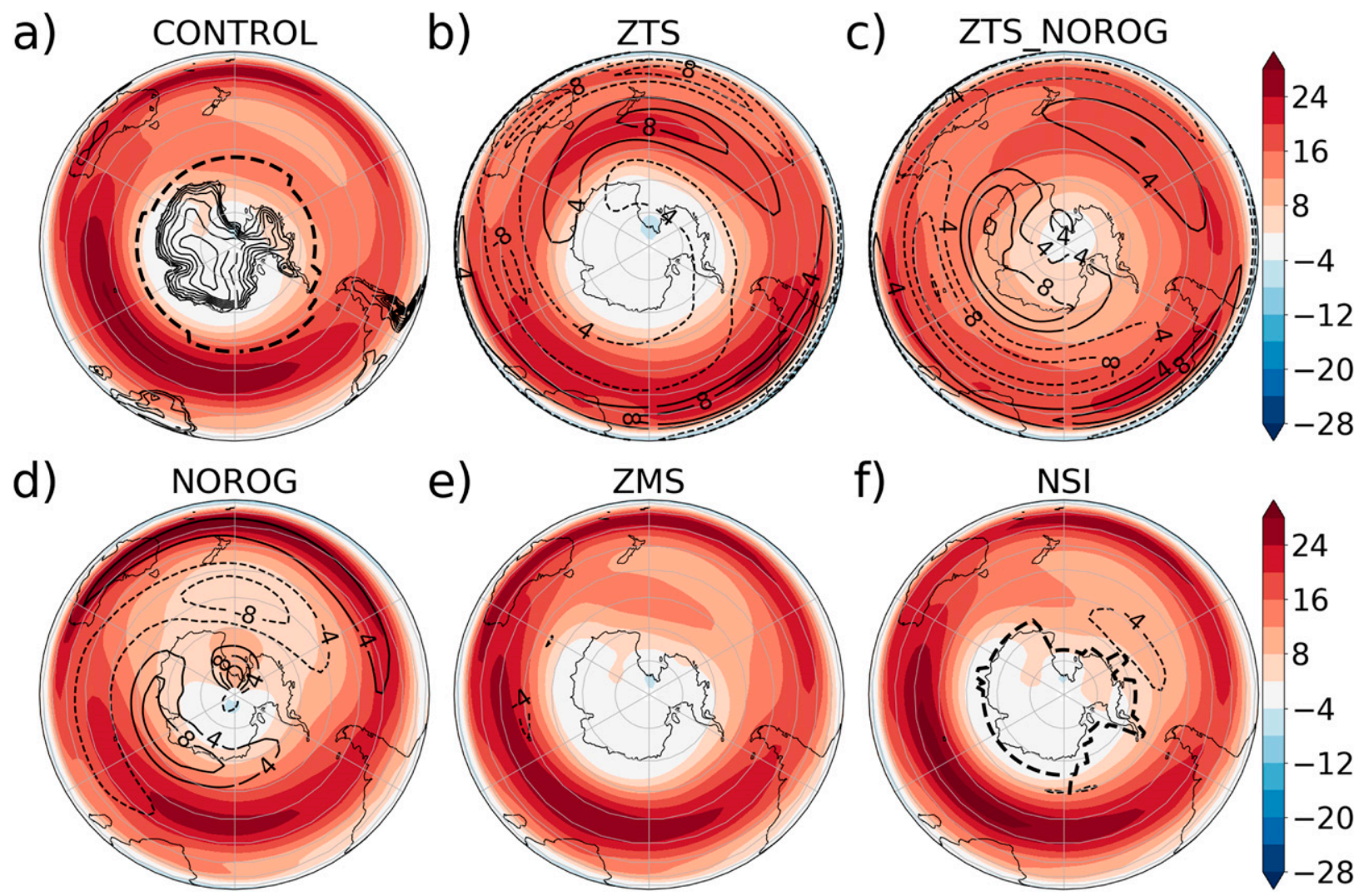

FIG. 5. As in Fig. 4, but for 500-hPa zonal wind. All panels show the climatology for the given run in colors and (b)-(f) show the climatology minus the CONTROL run in contours, with a contour interval of $4 \mathrm{~m} \mathrm{~s}^{-1}$. In (a) the $50 \%$ sea ice edge and topography (contoured every $500 \mathrm{~m}$ ) is shown and the $50 \%$ sea ice edge is shown in (f) for their respective runs.

orography, we set the relaxation temperature to follow a dry adiabatic lapse rate to the surface. The Newtonian cooling tendencies saved from this run are then used to create a climatology. Finally, a run without the plateau is performed with the seasonally varying cooling tendencies imposed, named COOL. The advantage of using this method is that it does not damp out eddy activity at high latitudes as is the case in the Newtonian relaxation run. Figure $6 \mathrm{~b}$ shows the temperature difference between NOROG and COOL, which is similar to the difference between NOROG and CONTROL. The main difference is a cold anomaly in the lower stratosphere between $60^{\circ}$ and $70^{\circ} \mathrm{S}$. The lower tropospheric temperature perturbation is of the same magnitude, with a peak of 6-7 K. It should be noted that while only the zonal mean temperature difference between COOL and NOROG is shown, the applied cooling is substantially zonally asymmetric.

In Fig. 7, a comparison is made of the 500-hPa zonal wind fields in CONTROL, NOROG, and COOL. It is clear that even with strong cooling of polar temperatures, the wind change from the COOL run is very similar to NOROG (Figs. 7b,c). For instance in Fig. 7c, the weakening of the flow over the South Pacific region remains much the same, as does the strengthening of the flow near the East Antarctic coastline. It might be expected that cooling would increase the local baroclinicity and promote stronger winds, but this only occurs at high latitudes and the flow in the midlatitudes remains severely weakened with respect to CONTROL. This indicates that the removal of the mechanical effects of the orography itself and the subsequent effects on eddy propagation are likely more important in altering the midlatitude circulation than the associated temperature perturbation.

\section{b. Effect on circulation}

We have so far noted that the circulation changes associated with flattening Antarctic orography are zonally asymmetric, with significant weakening of zonal wind over the South Pacific (Fig. 5). However, following many of the previous papers that have studied the effect of Antarctic orography on circulation we start by focusing on the zonal mean.

In Fig. 8, we plot the zonal mean momentum flux, heat transport, and kinetic energy, associated with transient eddies. In calculating each of these quantities, daily mean $u, v$, and $T$ have each been high-pass filtered using a 10-day Lanczos filter (Duchon 1979), indicated by primes. At high latitudes the CONTROL run sees an equatorward flux of eddy momentum (Fig. 8a), which is absent in NOROG. The absence of this flux reduces the convergence of eddy momentum in midlatitudes, hence the weakened midlatitude winds in NOROG (Figs. 5d, 7b), consistent with Singh et al. (2016). We suggest that the changes to high-latitude eddy momentum flux are likely linked 

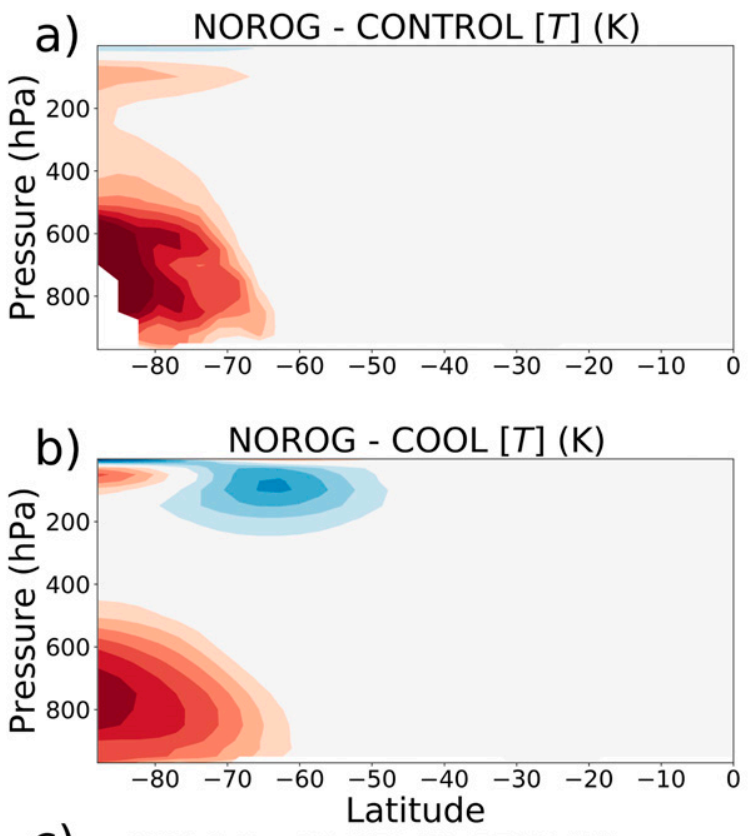

C)

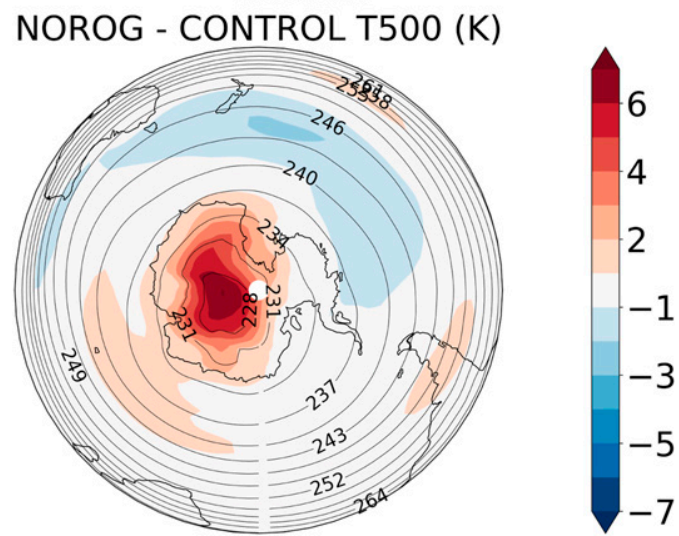

FIG. 6. Temperature differences between the CONTROL, NOROG, and COOL runs in JJA. The zonal mean temperature difference is shown for (a) NOROG - CONTROL and (b) NOROG COOL, and (c) the temperature difference on the $500-\mathrm{hPa}$ level is shown for NOROG - CONTROL. In (c), contours indicate the CONTROL climatology values, with contour interval $3 \mathrm{~K}$.

to the removal of the orographic slope and will investigate this further in section 6. High-latitude eddy heat flux is enhanced in NOROG as eddies are no longer confined to the coastline around Antarctica (Fig. 8b). However, eddy heat flux is also reduced in midlatitudes with respect to CONTROL, which is consistent with the decrease in eddy kinetic energy seen in Fig. 8c. The changes to midlatitude heat flux are in contrast to Mechoso (1981), who found much more substantial increases in eddy heat flux associated with removing the Antarctic Plateau. We also plot eddy statistics for the COOL run, in which a high-latitude cooling tendency has been applied. In this run, the poleward heat flux south of $60^{\circ} \mathrm{S}$ is enhanced in comparison to NOROG, in order to balance the cooling (Fig. 8b). However, the COOL zonal mean momentum fluxes are almost identical to those of NOROG (Fig. 8a), consistent with the similar zonal wind climatologies in Figs. $7 \mathrm{~b}$ and $7 \mathrm{c}$. Interestingly, eddy kinetic energy is greater at high latitudes in NOROG and COOL than in CONTROL, even though the momentum flux is very weak there. It appears that even if the magnitude of high-latitude eddy kinetic energy is lower in CONTROL, the eddies are more efficient at transporting momentum northward than in NOROG and COOL. A similar picture is seen in Fig. 9 with zonal wind and EP flux diagnostics (Edmon et al. 1980), which indicate the propagation of wave activity. EP flux is defined under the quasigeostrophic approximation as

$$
F=a \cos (\phi)\left[-\left(u^{*} v^{*}\right), f \frac{\left(v^{*} \theta^{*}\right)}{\theta_{p}}\right],
$$

where $u$ and $v$ are respectively the daily zonal and meridional wind, $f$ is the Coriolis parameter, and $\theta$ is the potential temperature. The radius of Earth is $a$, while $p$ and $\phi$ are the pressure and meridional coordinates. Square brackets represent the zonal mean, asterisks indicate departures from the zonal mean, and $\theta_{p}$ is the derivative of the potential temperature climatology with respect to pressure. No filtering is applied to $u$ and $v$ in Fig. 9, although if a high-pass filter is used the resulting figures are similar, whereas vectors are substantially diminished when using monthly mean data. This indicates that transient eddies dominate the observed changes over stationary eddies. The vectors are plotted following the convention of Edmon et al. (1980).

In the CONTROL run, the zonal mean zonal wind peaks at around $50^{\circ} \mathrm{S}$ in the lower troposphere and is close to zero over Antarctica. EP flux vectors indicate that waves propagate upward in the lower troposphere and then mostly equatorward, strengthening the surface westerlies and eddy-driven jet. On the poleward side of the jet, vectors are directed poleward, suggesting an equatorward flux of momentum, which helps to maintain the jet on the poleward side. In agreement with previous authors, flattening Antarctica increases the zonal mean zonal wind south of $65^{\circ} \mathrm{S}$ and decreases it in midlatitudes (Mechoso 1981; Singh et al. 2016). This is consistent with the fact that in NOROG, there is no equatorward momentum flux reinforcing the poleward flank of the jet (Fig. 8a).

However, the zonal mean masks the considerable zonal structure to the changes seen in Fig. 10. In the CONTROL run, 700-hPa $v^{\prime} T^{\prime}$ is strongest over the Indian Ocean with weaker though still significant heat transport at mid- to high latitudes over the South Pacific. Without Antarctic orography, transient eddy heat transport is extended poleward over the South Atlantic and South Indian Oceans as in the zonal mean (Fig. 8b), but $v^{\prime} T^{\prime}$ is considerably diminished in the South Pacific region (Figs. 10b,c). Surprisingly, it thus appears that removal of the zonally asymmetric orography creates an even more asymmetric storm track. Figure 10 also shows horizontal E vectors (Hoskins et al. 1983), which provide a useful measure of transient wave activity flux on a given pressure level. The westerly acceleration by transient eddies is proportional to the horizontal divergence of the $\mathbf{E}$ vectors in a given region. $\mathbf{E}$ vectors are defined as 

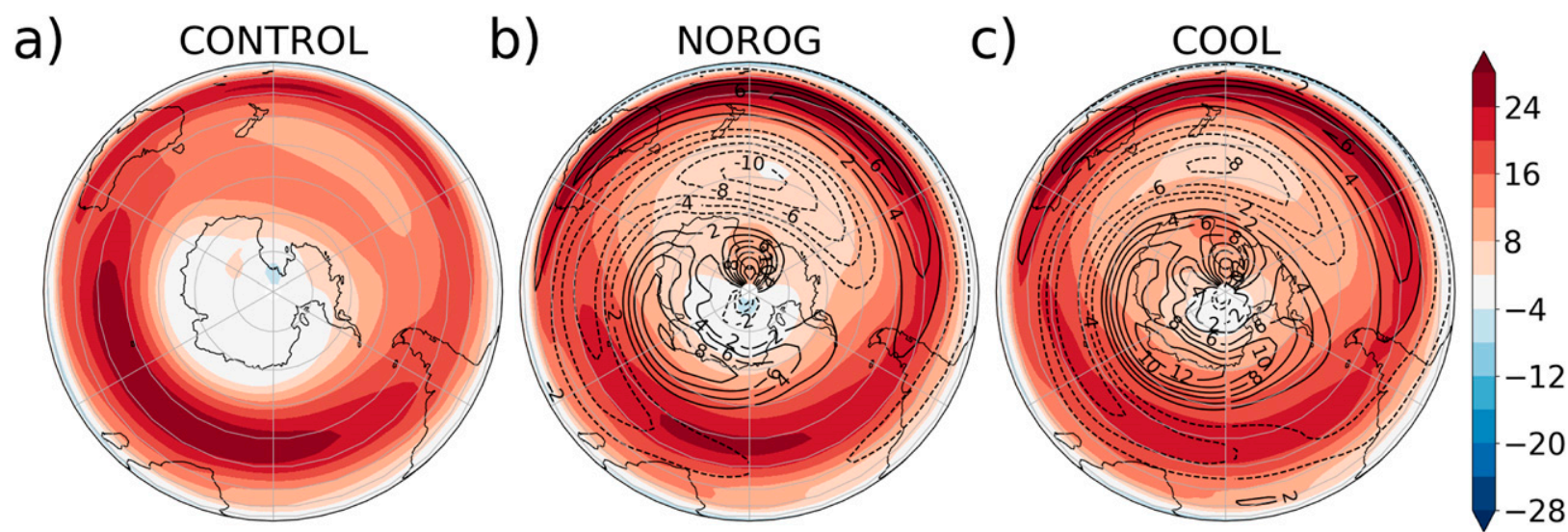

FIG. 7. 500-hPa zonal wind in the run with cooling imposed. The climatology is shown by colors for (a) CONTROL, (b) NOROG, and (c) COOL; in (b) and (c) contours indicate the difference from CONTROL with contour interval $2 \mathrm{~m} \mathrm{~s}^{-1}$.

$$
\mathbf{E}=\left(\overline{v^{\prime 2}-u^{\prime 2}},-\overline{u^{\prime} v^{\prime}}\right)
$$

with primes again indicating that the data have been 10-day high-pass filtered and overbars representing time averages. As was the case with $v^{\prime} T$, wave activity is abruptly reduced over the high-latitude South Pacific upon flattening Antarctica. The meridional component of $\mathbf{E}$ indicates the transient meridional flux of eddy momentum and this dominates the differences between the two runs at high latitudes (Fig. 10c), consistent with Figs. 8a and 9.

Thus far it has become clear that the largest midlatitude circulation changes in response to flattening Antarctica occur in the South Pacific region (Figs. 5 and 10), downstream of the most significant orography. In addition to the development of local instabilities, the eddies that reinforce the mean flow are

\section{a)}

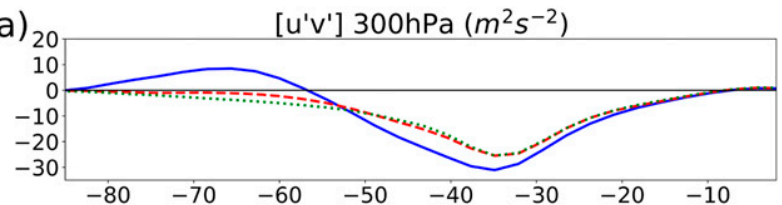

b)
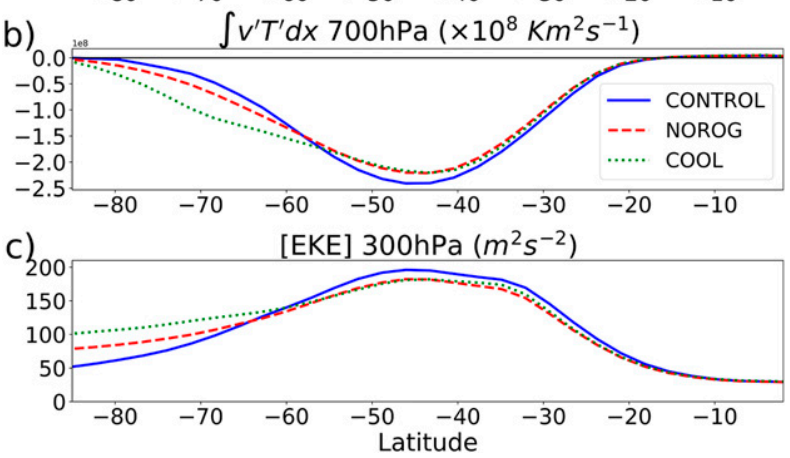

FIG. 8. Zonal mean eddy statistics for CONTROL (solid), NOROG (dashed), and COOL (dotted). (a) Zonal mean transient northward eddy momentum flux $u^{\prime} v^{\prime}$ at $300 \mathrm{hPa}$, (b) zonally integrated transient northward eddy heat flux $v^{\prime} T^{\prime}$ at $700 \mathrm{hPa}$ and (c) transient eddy kinetic energy $u^{\prime 2}+v^{\prime 2}$ at $300 \mathrm{hPa}$. In (b), $v^{\prime} T^{\prime}$ is undefined under orography, and hence $v^{\prime} T^{\prime}$ is integrated over all valid longitudes to show total transient eddy heat transport. often generated from farther west by the process of downstream development (Chang and Orlanski 1993; Hoskins and Hodges 2005). To investigate the role that Rossby waves from upstream might play, we plot lagged correlations of meridional wind in Fig. 11 as in Chang $(1993,1999)$. A base point is chosen (here $62^{\circ} \mathrm{S}, 180^{\circ}$, indicated by the white cross) before correlations between $300-\mathrm{hPa}$ meridional wind at that point and meridional wind at 850 and $300 \mathrm{hPa}$ at all other grid points are calculated and plotted. In the CONTROL run, meridional wind anomalies over the South Pacific are associated with a Rossby wave train from the Indian Ocean. This initially propagates southeast and continues eastward toward South America, refracting equatorward past about $200^{\circ} \mathrm{E}$. Comparing correlations with 850 and $300 \mathrm{hPa}$, there is a close correspondence between anomalies at the two levels, with a slight westward tilt with height indicating the wave has a small baroclinic component. In contrast to the clear Rossby wave train in CONTROL, anomalies in the NOROG run are more localized. This absence of coherent wave activity over the South Pacific in NOROG is consistent with the weakened midlatitude flow there (Fig. 5e). It is likely that the equatorward momentum flux on the poleward side of the jet seen in the CONTROL run (Figs. 8a, 9, and 10a,c) reinforces the jet and enables it to act as a waveguide for transient waves. Removing the orography removes this momentum flux, weakens the Indian Ocean jet, and hence makes Rossby wave propagation into the South Pacific less favorable. This is consistent with Codron (2007), who found that South Pacific eddy forcing is strongly influenced by zonal wind anomalies upstream, over the Indian Ocean. We therefore suggest that the reduced transient eddy heat flux and weak $\mathbf{E}$ vectors seen over the South Pacific in Fig. $8 \mathrm{~b}$ are related to the decrease in wind strength upstream via reductions in downstream development.

\section{A barotropic model of orographic effects on transient eddies}

In the absence of Antarctic orography, the jet stream weakens substantially in the Indian Ocean region (Fig. 5e) with 
a)

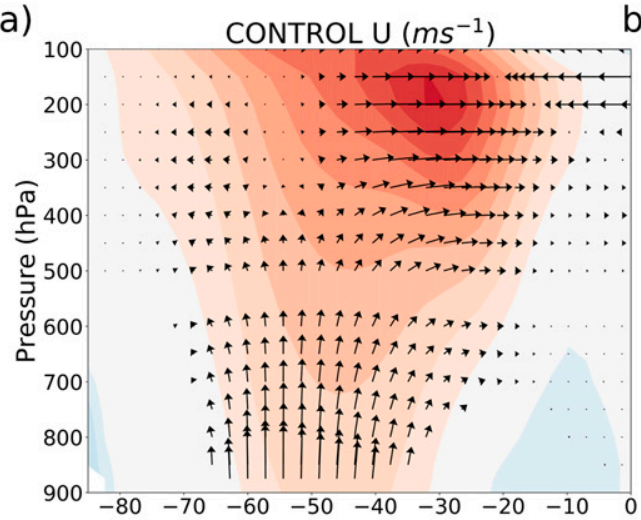

b)

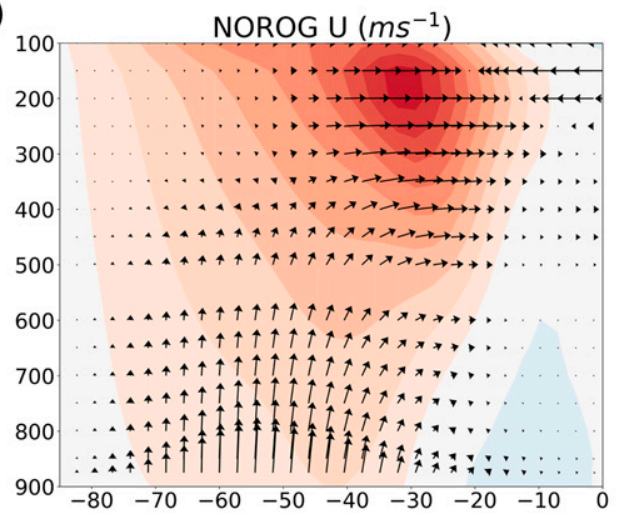

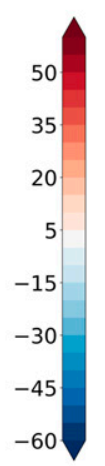

c)

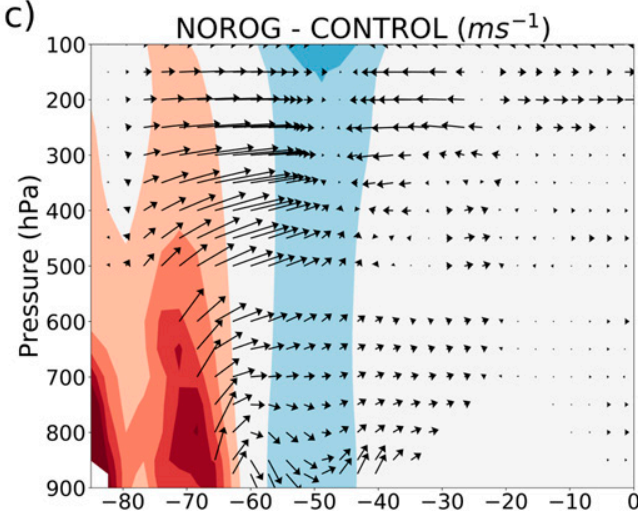

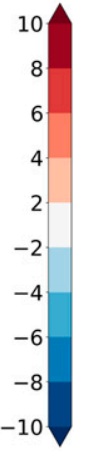

FIG. 9. EP flux vectors and zonal mean zonal wind for (a) CONTROL (b) NOROG, and (c) NOROG CONTROL. EP flux vectors are not plotted in regions of significant orography.

implications for the South Pacific downstream (Fig. 10). Our argument so far, concerning reductions in eddy momentum flux changing the circulation, has a degree of circularity to it. This is because the interaction between eddies and the mean flow is a two-way process; eddies generate the mean winds, and the mean winds alter eddy propagation and also affect eddy generation through baroclinic instability. We now suggest an explanation for the influence of orography on eddy momentum fluxes using a barotropic model with bottom orography, stirred over a range of wavenumbers. Using this model has the

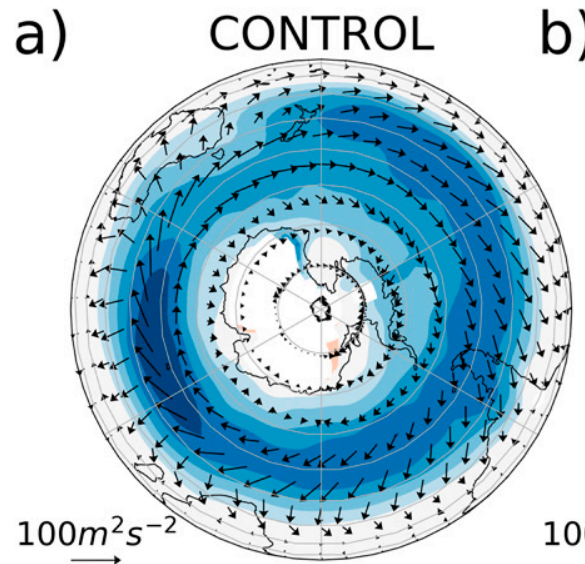

a)

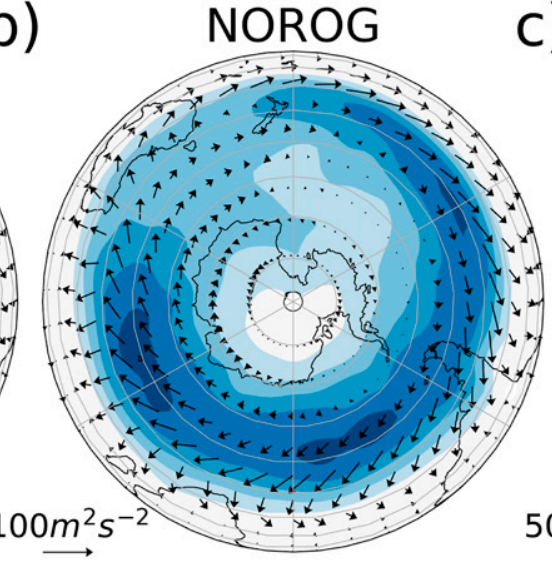

b)
C) NOROG - CONTROL

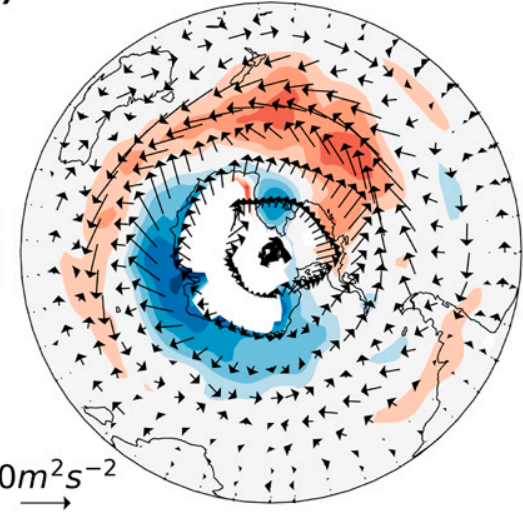

10

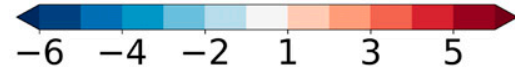

FIG. 10. Horizontal 300-hPa E vectors and 700-hPa transient eddy heat flux $v^{\prime} T^{\prime}$ ( $\mathrm{K} \mathrm{m} \mathrm{s}^{-1}$; colors) for (a) CONTROL, (b) NOROG, and (c) NOROG - CONTROL. As before, primes indicate filtering with a 10-day high-pass filter. 

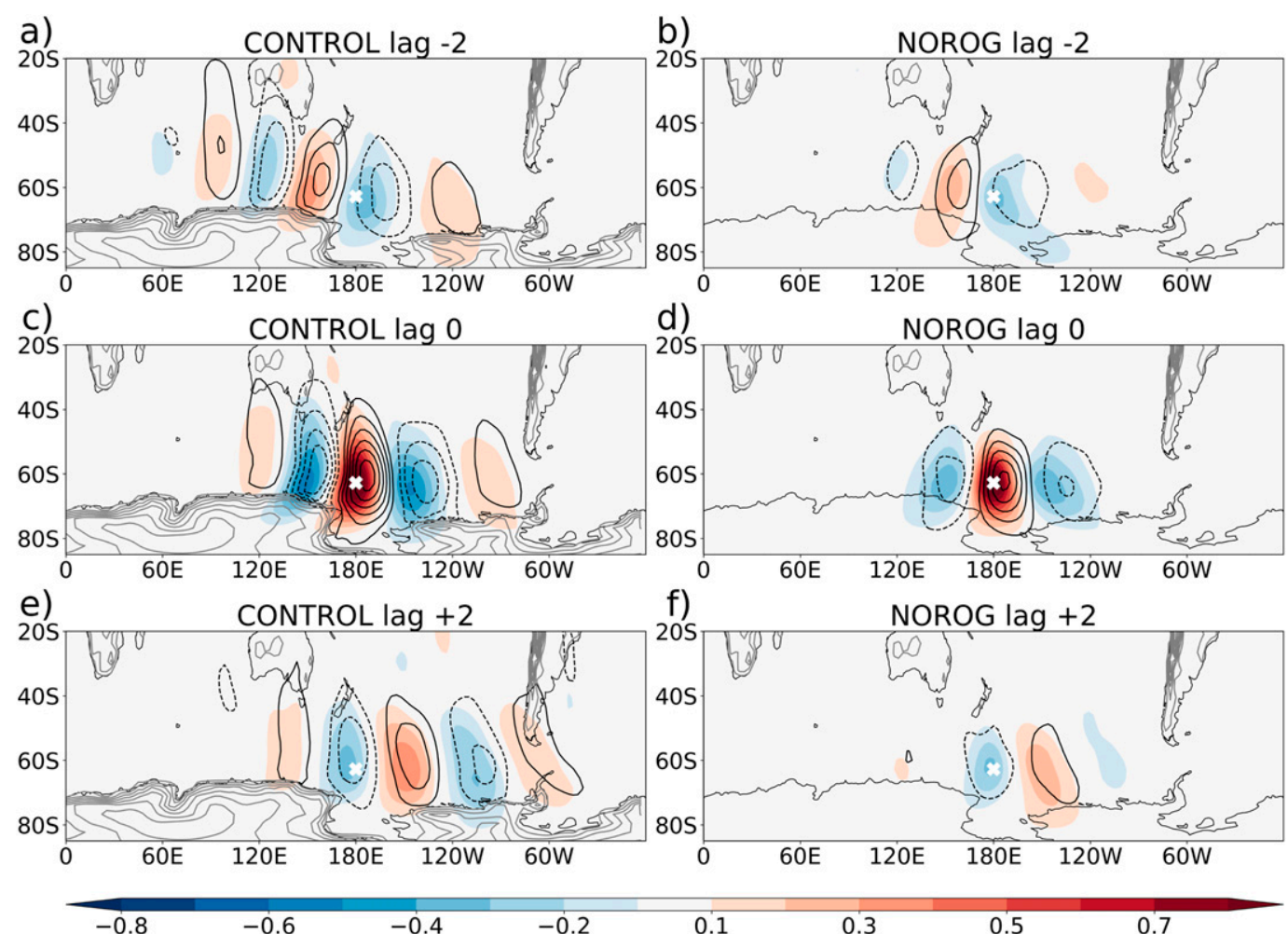

$-0.6$

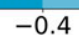

$-0.2$

0.3

0.5

0.7

FIG. 11. Lagged correlations of meridional wind, as described in the text. Correlations of 300-hPa meridional wind at the point $62^{\circ} \mathrm{S}, 180^{\circ}$ (denoted by a cross) with $300-\mathrm{hPa}$ wind (colors) and $850-\mathrm{hPa}$ wind (contours) are shown in all panels. In both cases the contour interval is 0.1 . Topographic contours are also displayed in light gray with contours every $500 \mathrm{~m}$, beginning at $500 \mathrm{~m}$.

advantages that it is conceptually simple and allows a better understanding of causality, as the eddy momentum fluxes generate the zonal winds in this model, but the winds do not affect the stirring that generates the eddies. It is worth noting that the differing mean-wind profiles will have some effect on eddy propagation. However, the key point is that the stirring itself has the same properties in each run, meaning that any differences between runs can ultimately be attributed to the presence or absence of orography.

The model is the same as in Vallis et al. (2004) and Barnes and Hartmann (2011) with the exception that we allow the depth of the fluid layer to vary in the meridional direction. The result of this is to add another term to the barotropic vorticity equation, which effectively modifies the planetary vorticity gradient along gradients of orography. The key idea is that the presence of an orographic slope at high southern latitudes means that meridional exchange of air masses across the orographic slope will result in a northward flux of vorticity/ westerly momentum (e.g., James 1989; Egger 1991). That is, an air column moving southward will be squashed and, by conservation of potential vorticity, will become more anticyclonic. Conversely, an air column moving northward will be stretched and thus become anomalously cyclonic. We will demonstrate this effect by comparing runs with and without high-latitude orography and then explain how the northward vorticity flux is achieved.
We begin with a layer of fluid with depth $H$ and relative vorticity $\zeta$. We write the depth of the fluid as $H(\phi)=H_{T}-$ $h_{B}(\phi)$ in which $H_{T}$ is the height of the tropopause, set as $10 \mathrm{~km}$, and $h_{B}$ is the bottom topography. Potential vorticity $P$ is given by the following:

$$
P=\frac{\zeta+f}{H}
$$

as in Vallis (2017). Bottom topography is given a profile which is zero to the north of $65^{\circ} \mathrm{S}$ and then slopes upward to a maximum at $90^{\circ} \mathrm{S}$. A cosinusoidal profile is used for the slope, which is shown by a thick curve in Fig. 12c and mathematically described as follows:

$$
h_{B}(\phi)= \begin{cases}h_{0} \cos \left[\frac{90}{\phi_{w}}(\phi+90)\right], & \phi \leq-90+\phi_{w}, \\ 0, & \phi>-90+\phi_{w},\end{cases}
$$

with $\phi_{w}=25^{\circ}$ and $h_{0}=3 \mathrm{~km}$. The model is integrated on a sphere and takes the following form:

$$
\frac{\partial \zeta}{\partial t}+\frac{u}{a \cos \phi} \frac{\partial \zeta}{\partial \lambda}+\frac{v}{a} \frac{\partial \zeta}{\partial \phi}+\left(\beta+\frac{\zeta+f}{H} \frac{\partial h_{B}}{a \partial \phi}\right) v=S-r \zeta+\kappa \nabla^{4} \zeta
$$

where $\lambda$ and $\phi$ are the zonal and meridional coordinates respectively. Similar to Vallis et al. (2004) and Barnes and 

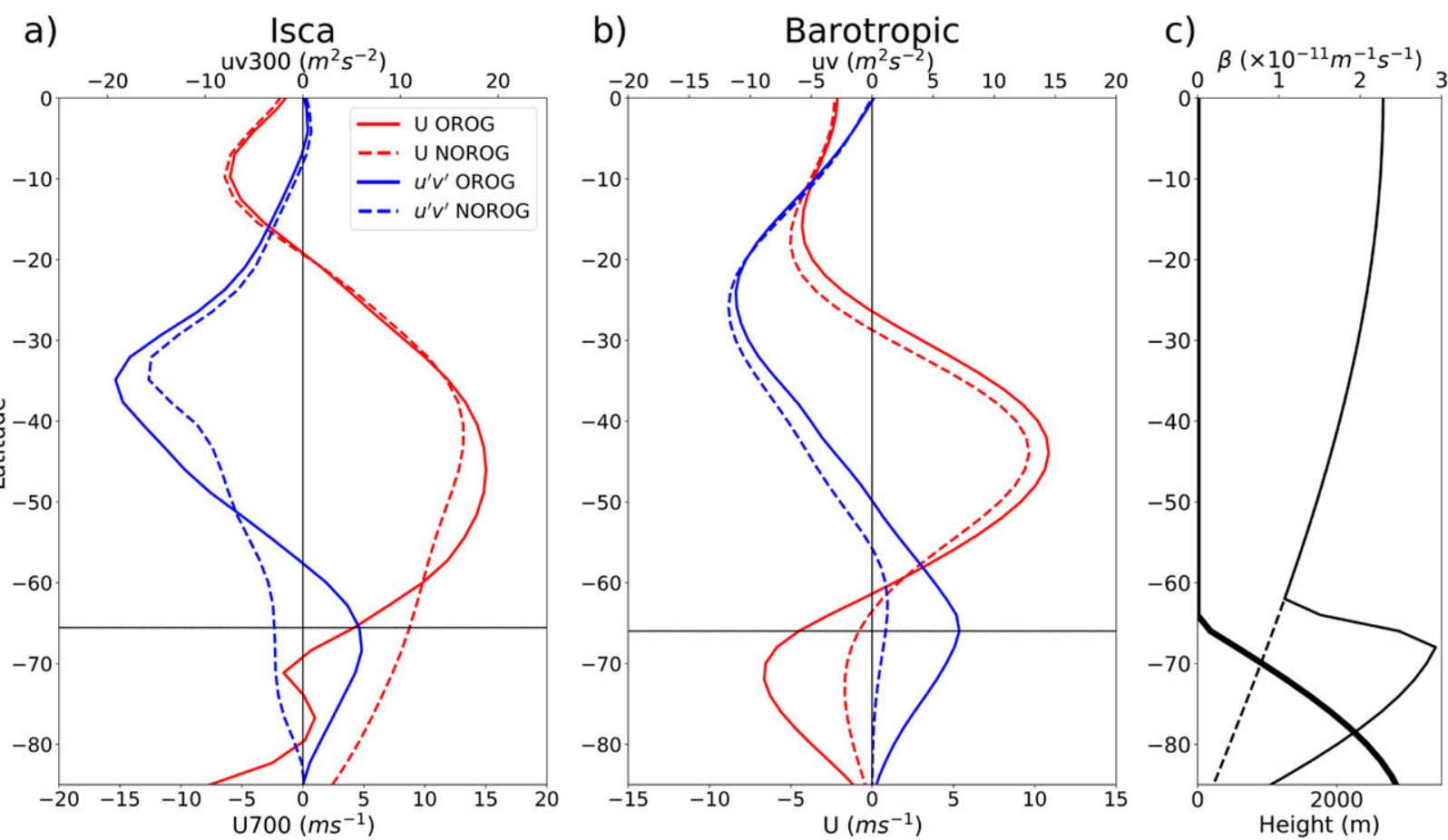

FIG. 12. Zonal mean momentum flux (blue) and zonal mean zonal wind (red) for (a) Isca and (b) barotropic model runs. Runs with Antarctic orography are shown by solid curves, while runs without orography are indicated by dashed curves. In (a) the eddy momentum flux $u^{\prime} v^{\prime}$ is shown on the $300-\mathrm{hPa}$ level and zonal mean zonal wind is shown at $700 \mathrm{hPa}$. A horizontal line in (a) marks the most northward latitude of the Antarctic continent and a similar line in (b) marks the edge of the orography. (c) Orographic height in the barotropic model is shown by the thick curve and $\beta$ is plotted as a function of latitude (dashed) with an estimation of the effective "orographic $\beta$ " (solid). The orographic $\beta$ term is a function of vorticity so the time-mean value is shown.

Hartmann (2011), we apply stirring $S$, which parameterizes baroclinic instability: $S$ is an Ornstein-Uhlenbeck process defined as

$$
S_{l m}=\left(1-e^{2 d t / \tau}\right)^{1 / 2} Q^{i}+e^{-d t / \tau} S_{l m}^{i-1},
$$

where $l$ and $m$ are respectively the total and zonal wavenumber, $d t$ is the time step (900 s), $i$ is an index for the current time step, and $\tau$ is a decorrelation time scale equal to 2 days; $Q^{i}$ is a random number drawn from a uniform distribution in the range $\left[-7 \times 10^{-11}, 7 \times 10^{-11}\right]$. The stirring is only applied in midlatitudes and this is achieved by multiplying $S$ by a Gaussian function of half-width $12^{\circ}$, centered on $45^{\circ} \mathrm{S}$. Linear Ekman damping is employed with coefficient $r=1 / 5$ day $^{-1}$ and the loss of vorticity at the smallest, unresolved scales is simulated via fourth-order hyperdiffusion.

\section{Barotropic model results}

As in the full Isca model, the barotropic model runs with and without orography are notably different in terms of momentum fluxes near the pole. Figure 12 shows the zonal mean zonal wind and transient eddy momentum transport, $u^{\prime} v^{\prime}$, in both models. In both Isca and the barotropic runs, the model runs without orography (dashed curves) exhibit either weak or poleward momentum fluxes at high latitudes in contrast to the runs with orography (solid curves), which show substantial equatorward momentum fluxes. In the latter cases this has a clear impact on the jet as the wind is reduced at high latitudes and enhanced in midlatitudes. The Isca and barotropic runs without orography do differ in that momentum fluxes in the latter are positive (equatorward) at high latitudes, whereas momentum fluxes are negative (poleward) at all latitudes in the former. Previous studies have shown that flattening Antarctica results in enhanced baroclinic eddy growth at high latitudes (Simmonds and Law 1995; Walsh et al. 2000; Singh et al. 2016), consistent with the greater high-latitude eddy kinetic energy in NOROG than in CONTROL (Fig. 10c). This provides a new source of eddy activity in NOROG, allowing equatorward momentum fluxes from higher latitudes than in CONTROL. This process is absent in the barotropic model runs. Note that in the Isca runs, momentum fluxes are shown at $300 \mathrm{hPa}$ as these are largest at this level, whereas winds are shown at $700 \mathrm{hPa}$ to isolate the eddy-driven jet (e.g., Woollings et al. 2010). We also define the effective planetary vorticity gradient as

$$
\beta_{\mathrm{eff}}=\frac{2 \Omega \cos (\phi)}{a}+\frac{\zeta+f}{H} \frac{\partial h_{B}}{a \partial \phi}
$$

and plot this in Fig. 12c. This shows the sharp increase in the meridional vorticity gradient that the orography generates in the barotropic model. 
a)

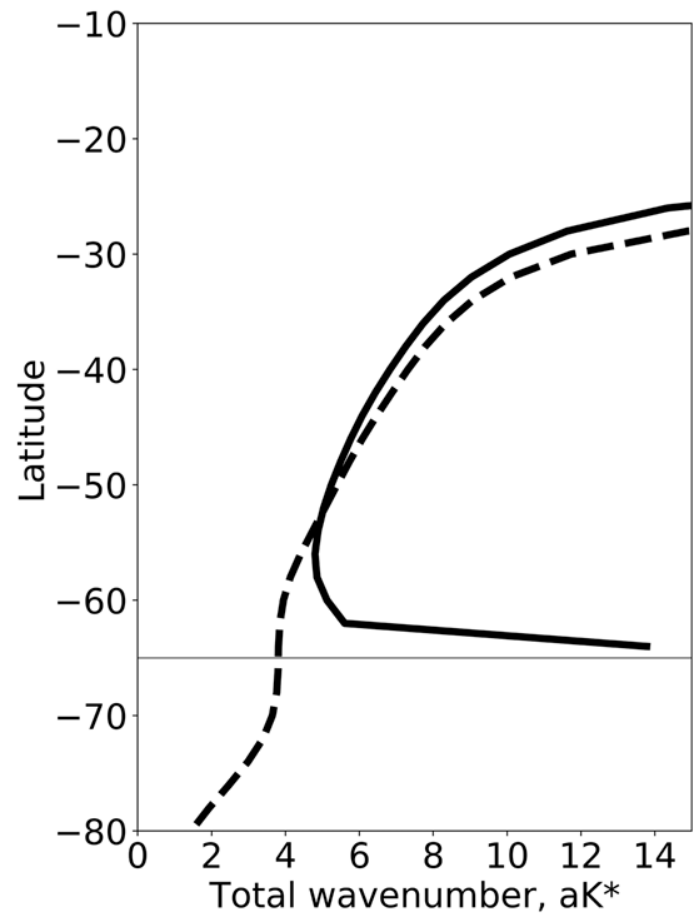

b)

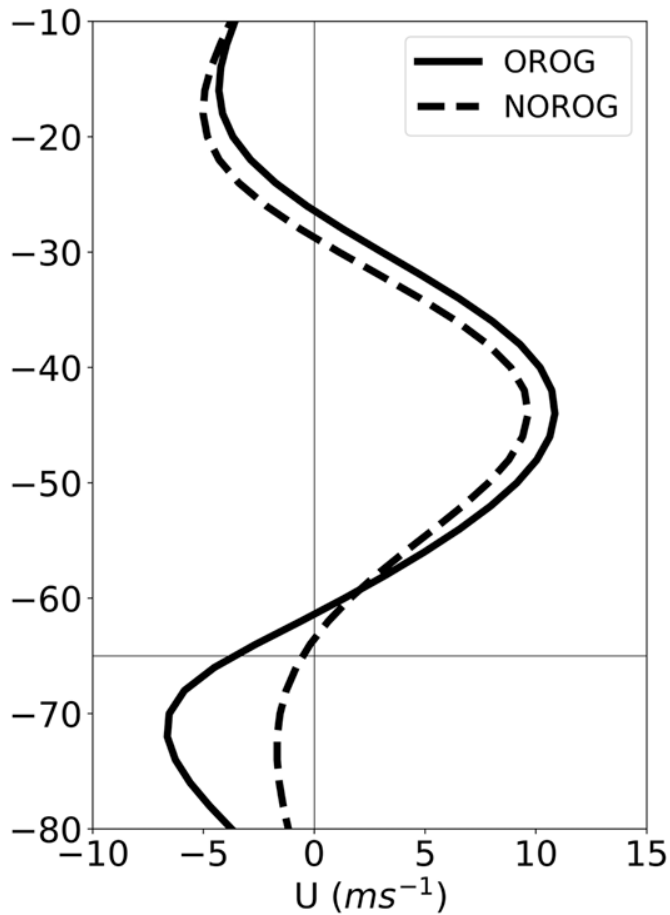

FIG. 13. (a) Total wavenumber and (b) zonal wind in the barotropic model runs. A horizontal line at $65^{\circ} \mathrm{S}$ indicates the beginning of the bottom orography.

The total wavenumber framework of Hoskins and Karoly (1981) is helpful here in understanding the propagation of waves and hence the momentum fluxes that generate the mean flow. The total wavenumber $K^{*}$ is given by

$$
K^{*}=\cos (\phi)\left(\frac{\beta-\frac{\partial^{2} u}{\partial y^{2}}}{\bar{u}-c}\right)^{1 / 2}
$$

in which $\bar{u}-c$ is the zonal mean zonal wind minus the wave phase speed. In general, waves propagate toward higher $K^{*}$ until they encounter a turning latitude, where $K^{*}=k$, or a critical latitude, $\bar{u}=c$, at which $K^{*}$ becomes infinite and simple barotropic wave theory breaks down, sometimes associated with nonlinear wave breaking (Hoskins and Ambrizzi 1993). We replace $\beta$ with $\beta_{\text {eff }}$ as defined above, in our definition of $K^{*}$, to account for the additional orographic $\beta$ effect. Hence $K^{*}$ becomes

$$
K^{*}=\cos (\phi)\left(\frac{\beta_{\mathrm{eff}}-\frac{\partial^{2} u}{\partial y^{2}}}{\bar{u}-c}\right)^{1 / 2}
$$

In Fig. 13a, we see that without bottom orography, $K^{*}$ generally decreases with increasing latitude and so any waves propagating poleward will tend to encounter a turning latitude and refract equatorward, breaking in the subtropics. Hence the jet will mostly only be enhanced on its equatorward flank by eddy momentum fluxes. On the other hand, waves generated in midlatitudes in the presence of high-latitude orography can also refract poleward toward higher $K^{*}$. For this reason, in this case, there will also be a significant equatorward momentum flux from high latitudes, in agreement with Fig. 12 and the full $3 \mathrm{D}$ model runs. The profile of $K^{*}$ is partly shaped by the orographic $\beta$ term, but the critical latitude at $65^{\circ} \mathrm{S}$ is set by the latitude at which $\bar{u}=c$. Hence, the mean winds largely determine the propagation of transient eddies. However, it is worth emphasizing that the only forcing difference that can lead to changes in the wind and the eddy fluxes between the runs with and without orography is the orographic $\beta$ term, $[(\zeta+f) /$ $H]\left(\partial h_{B} / a \partial \phi\right) v$, as the eddy stirring is statistically identical. It can therefore be said that the increase in the jet speed is entirely due to the presence of high-latitude orography.

To check that both Isca and the barotropic models are achieving momentum fluxes in a similar way, we plot correlations of meridional wind in Fig. 14, as in Fig. 11, but for the base point $\left(62^{\circ} \mathrm{S}, 110^{\circ} \mathrm{E}\right)$ and at lag 0 . This base point is close to the most significant orography, which rises steeply over East Antarctica. We also plot correlations for ERA-Interim to connect the results back to observational data. The two models show a remarkable correspondence for both experiments and the orography runs agree well with ERA-Interim.

For runs with orography, correlations show a Rossby wave train, centered on the base point, with a distinctive southwestnortheast tilt to the positive meridional wind anomaly. This tilted pattern is characteristic of equatorward momentum flux. 

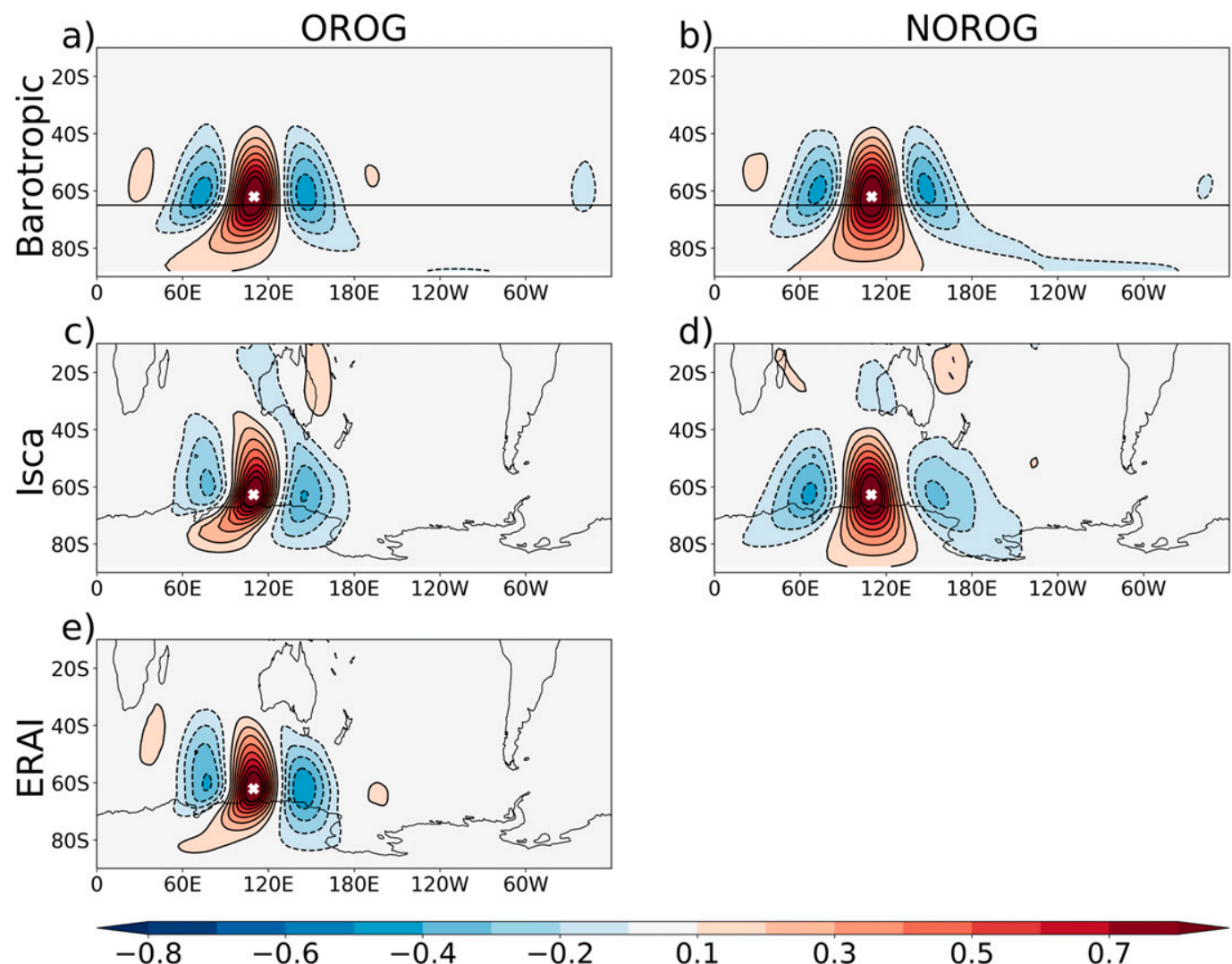

\section{1}

0.3

0.5

0.7

FIG. 14. 300-hPa meridional wind correlation maps as in Fig. 11 but for ERA-Interim, barotropic model runs, and Isca runs and using the base point $62^{\circ} \mathrm{S}, 110^{\circ} \mathrm{E}$ (marked by a white cross).

Downstream, the negative anomaly appears to follow the topographic gradient eastward and remains at high latitudes. This is less obvious in the barotropic model (with orography) but is clearer at lags +1 and +2 (Figs. S4 and S5 of the supplemental material). The waves do not appear to break, but may be propagating along the effective potential vorticity gradient that results from the orographic slope (Egger and Fraedrich 1987). The tilt is caused by the propagation of eddies toward higher $K^{*}$ as suggested by the poleward critical latitude in Fig. 13a. In contrast to these cases, the correlation patterns in runs without orography show a Rossby wave propagating southeastward from the west of the base point, reaching the base point and then refracting equatorward. While the waves exhibit a slight southwest-northeast tilt on reaching the base point, the poleward momentum flux associated with the equatorward refraction cancels this out. Correlations for the runs without orography also appear to pick out a lower wavenumber. This is particularly the case when comparing the Isca runs, as the CONTROL has a typical wavenumber of 4-5 while NOROG exhibits a wavenumber of around 3-4. Typical wavenumbers of 4-5 at high latitudes in the CONTROL run are in agreement with the observational study of Chang (1999, his Fig. 3). Generally only the lowest wavenumber waves are able to propagate to high latitudes, but it is likely that the increase in potential vorticity gradient associated with orography allows waves of a higher wavenumber to reach polar latitudes.
In summary, when a high-latitude orographic slope is imposed in a barotropic model with stochastic forcing, exchange of air masses across the orographic slope results in a vorticity flux away from the orography. In the steady state, transient eddies, generated by stirring in midlatitudes, propagate toward a critical latitude that is set by the presence of highlatitude easterlies along the orographic slope. The poleward propagation of eddies results in an equatorward momentum flux and thus the maintenance of a stronger eddy-driven jet. This is similar to the Indian Ocean sector where there is a steep orographic slope at high latitudes and a strong midlatitude jet. Conversely, in the barotropic model run with no orography, waves encounter a turning latitude at high latitudes, preventing poleward wave propagation on the poleward side of the jet, consistent with lagged correlation plots in the Isca NOROG run (Fig. 14b).

\section{Discussion and conclusions}

In this study we have investigated the processes shaping the wintertime Southern Hemisphere circulation by altering various boundary conditions in an idealized model. In agreement with previous work, the structure of tropical SSTs was found to be critical for the formation of a quasi-stationary Rossby wave, which creates the South Pacific split jet (Inatsu and Hoskins 
2004, 2006). In contrast, removing the zonally asymmetric components of midlatitude SST resulted in relatively weak changes to the overall circulation. Retreating sea ice back to the Antarctic continent also had a comparatively small impact on the circulation, although it did weaken the high-latitude jet over the southeast Pacific. That is not to say that such changes would not have significant impacts on the climate system, but rather that midlatitude SSTs and sea ice are not of first-order importance in setting the mean atmospheric circulation in the $\mathrm{SH}$.

In addition to tropical SSTs, we found the presence of orography over Antarctica to have a leading-order effect on midlatitude circulation. Without the Antarctic Plateau, eddy activity over the Indian Ocean increased and was able to penetrate farther poleward. However, high-latitude equatorward momentum fluxes also ceased, weakening the eddydriven jet. The largest changes occurred downstream in the South Pacific region as the storm track abruptly terminated over the Indian Ocean (illustrated by $v^{\prime} T^{\prime}$ in Fig. 10). Concomitantly, the mid- to high-latitude winds over the South Pacific severely weakened and the split jet was destroyed. While idealized, these experiments illustrate the dependence of the wintertime South Pacific circulation on the flow upstream over the Indian Ocean (e.g., Chang 1999; Codron 2007). Propagation of Rossby waves from the Indian Ocean to the South Pacific became less favorable in the absence of Antarctic orography (Fig. 11), likely because of the weakening of the Indian Ocean jet, making it less effective as a waveguide (Hoskins and Ambrizzi 1993). These results appear all the more intriguing when considering that Antarctic orography is itself considerably zonally asymmetric, and yet removing this feature results in an even more zonally asymmetric atmospheric circulation. We also noted that circulation anomalies associated with removal of tropical SST asymmetries and anomalies associated with flattening Antarctica, do not add linearly when both changes are imposed in the same run (Fig. 5c). This nonlinearity is particularly seen over the South Pacific and could be related to the dependence of the South Pacific on downstream propagation of transient Rossby waves, as discussed above.

Our results have broadly been in agreement with those of previous studies investigating the effect of Antarctic orography on circulation. For instance, we found a large warming at high latitudes and an increase in poleward heat flux at high latitudes upon flattening Antarctica (Mechoso 1981; Simmonds and Law 1995; Ogura and Abe-Ouchi 2001; Singh et al. 2016). At the same time, we found an increase in high-latitude westerly winds and a decrease in wind strength in midlatitudes (Mechoso 1981; Singh et al. 2016). Furthermore, we showed substantial zonal asymmetries to the midlatitude circulation response, with the largest changes occurring in the South Pacific region, a finding that was alluded to in Simmonds and Law (1995). However, in contrast to Simmonds and Law (1995), we have found that the temperature perturbation resulting from flattening Antarctica is of lesser importance in determining changes to large-scale atmospheric dynamics (Fig. 7). Rather, we have shown that it is the presence of the orographic slope itself that altered the dynamics of eddies, increasing the convergence of eddy momentum in the midlatitudes. Flattening the orography in Isca enabled transient eddies to penetrate farther south over the Antarctic continent, as measured in eddy kinetic energy and heat transport. Despite this, the eddy momentum fluxes over Antarctica are considerably stronger in the case with orography.

We have provided an explanation for this influence of Antarctic orography on midlatitudes using a simple barotropic model with bottom topography varying in latitude. The effect of this was to add an additional orographic $\beta$ term that modified high-latitude eddy momentum fluxes, enhancing the eddydriven jet in midlatitudes. The term $\beta$ is relatively weak at high latitudes (Fig. 12c), but as a result of the orographic $\beta$ effect and changes to the zonal mean wind profile it appears that waves tend to refract poleward toward the greater potential vorticity gradient (Fig. 14). The eddies thus exhibit a southwest-northeast tilt at high latitudes, which is effective at transporting momentum equatorward, strengthening the jet. While simplified, we have shown that the output of this model corresponds closely, at least in a qualitative sense, with effects seen in the full 3D model. We have also shown that the eddy tilt seen in the barotropic and 3D models is present in observations (Fig. 14). The importance of eddy momentum fluxes over Antarctica was also emphasized by Juckes et al. (1994). Surface cooling over the continent results in downslope winds from the center of the continent toward the coast. The Coriolis torque acting on these generates surface easterly winds, and the drag on these constitutes a source of westerly momentum for the atmosphere over Antarctica. Equatorward transient eddy momentum fluxes play an important role in balancing this source term, and our results suggest that eddy refraction by the orographic potential vorticity gradient is a key mechanism that provides these fluxes.

Many CMIP5 models struggle to capture the polar front branch of the South Pacific split jet seen in reanalysis data. The fine details of Antarctic orography may be smoothed out due to the coarse resolution of climate models, but the orographic effects on eddies that we have considered are unlikely to be sensitive to these details. However, the present study does suggest that both the strength of the wind and the nature of Rossby wave propagation over the Indian Ocean are important for the split jet. Consequently, we have shown that in order to correctly capture the South Pacific jet structure, a model must adequately capture the processes governing the upstream flow.

On paleo time scales, Antarctic ice sheets have undergone considerable change, and this is likely to have had a substantial effect on SH midlatitude circulation. For example, Justino et al. (2014) performed simulations with Antarctic orography lowered by $25 \%$, mimicking conditions in the mid- to late Miocene ( $\sim 15$ million years ago) and found weakened zonal mean zonal winds in the midlatitudes, consistent with the present study. However, it would be of interest to study the effect of altered Antarctic orography on $\mathrm{SH}$ circulation more systematically and quantitatively compare these changes with the effects of other long-term forcing variations such as changes to greenhouse gas concentrations and ocean circulation.

This work has concerned the asymmetry of the SH mean state, however studies have noted that the response of wintertime $\mathrm{SH}$ circulation under climate change is also considerably 
zonally asymmetric (Simpson et al. 2014; Grose et al. 2017; Patterson et al. 2019). It would be of interest to investigate which forcing mechanisms are responsible for driving these responses and how they relate to the mean state. The results of the present study lead us to speculate that changes to tropical SSTs are likely to be important, while sea ice retreat and midlatitude SSTs are less likely to play a major role in driving changes in the asymmetry. Indeed, several studies have shown links between observed high southern latitude circulation changes and tropical SST trends (Simpkins et al. 2014; Li et al. 2015). Our findings concerning the dependence of the South Pacific eddy-driven jet on the flow upstream are also relevant here, as any changes to the Indian Ocean region could potentially have an even greater impact on the Pacific.

Acknowledgments. We thank three anonymous reviewers for their comments and suggestions that improved the manuscript. We also thank Ronald Li and Chris O'Reilly for helpful discussions on this work. Finally, we thank ECMWF for the use of ERA-Interim reanalysis data, which was downloaded from the ECMWF website (https://www.ecmwf.int/en/forecasts/ datasets/browse-reanalysis-datasets). Model data from the simulations in this study is available from the authors upon request. Matthew Patterson was funded by the Natural Environment Research Council (Grant NE/L002612/1), while Tom Bracegirdle was also supported by the Natural Environment Research Council through the British Antarctic Survey research programme Polar Science for Planet Earth. Neil Lewis was funded by the Science and Technology Facilities Council (Grant ST/ S505638/1).

\section{REFERENCES}

Arakelian, A., and F. Codron, 2012: Southern Hemisphere jet variability in the IPSL GCM at varying resolutions. J. Atmos. Sci., 69, 3788-3799, https://doi.org/10.1175/JAS-D-12-0119.1.

Ayres, H., and J. Screen, 2019: Multimodel analysis of the atmospheric response to Antarctic sea ice loss at quadrupled $\mathrm{CO}_{2}$. Geophys. Res. Lett., 46, 9861-9869, https://doi.org/10.1029/ 2019GL083653.

Bals-Elsholz, T. M., E. H. Atallah, L. F. Bosart, T. A. Wasula, M. J. Cempa, and A. R. Lupo, 2001: The wintertime Southern Hemisphere split jet: Structure, variability, and evolution. J. Climate, 14, 4191-4215, https://doi.org/10.1175/15200442(2001)014<4191:TWSHSJ > 2.0.CO;2.

Barnes, E. A., and D. L. Hartmann, 2011: Rossby wave scales, propagation, and the variability of eddy-driven jets. J. Atmos. Sci., 68, 2893-2908, https://doi.org/10.1175/JAS-D-11-039.1.

Betts, A. K., and M. J. Miller, 1986: A new convective adjustment scheme. Part II: Single column tests using GATE wave, BOMEX, ATEX and Arctic air-mass data sets. Quart. J. Roy. Meteor. Soc., 112, 693-709, http://doi.org/10.1002/qj.49711247308.

Bracegirdle, T. J., E. Shuckburgh, J. B. Sallee, Z. Wang, A. J. S. Meijers, N. Bruneau, T. Phillips, and L. J. Wilcox, 2013: Assessment of surface winds over the Atlantic, Indian, and Pacific Ocean sectors of the southern ocean in CMIP5 models: Historical bias, forcing response, and state dependence. J. Geophys. Res. Atmos., 118, 547-562, http://doi.org/10.1002/jgrd.50153.

Brayshaw, D. J., B. Hoskins, and M. Blackburn, 2008: The stormtrack response to idealized SST perturbations in an aqua- planet GCM. J. Atmos. Sci., 65, 2842-2860, https://doi.org/ 10.1175/2008JAS2657.1.

, ——, and — 2009: The basic ingredients of the North Atlantic storm track. Part I: Land-sea contrast and orography. J. Atmos. Sci., 66, 2539-2558, https://doi.org/10.1175/2009JAS3078.1.

— - _ and _ 2011: The basic ingredients of the North Atlantic storm track. Part II: Sea surface temperatures. J. Atmos. Sci., 68 , 1784-1805, https://doi.org/10.1175/2011JAS3674.1.

Chang, E. K. M., 1993: Downstream development of baroclinic waves as inferred from regression analysis. J. Atmos. Sci., 50, 2038-2053, https://doi.org/10.1175/1520-0469(1993)050<2038: DDOBWA $>2.0 . \mathrm{CO} ; 2$.

_- 1999: Characteristics of wave packets in the upper troposphere. Part II: Seasonal and hemispheric variations. J. Atmos. Sci., 56, 1729-1747, http://doi.org/10.1175/15200469(1999)056\%3C1729:COWPIT\%3E2.0.CO;2.

—, and I. Orlanski, 1993: On the dynamics of a storm track. J. Atmos. Sci., 50, 999-1015, https://doi.org/10.1175/15200469(1993)050<0999:OTDOAS > 2.0.CO;2.

Clough, S. A., M. W. Shephard, E. J. Mlawer, J. S. Delamere, M. J. Iacono, K. Cady-Pereira, S. Boukabara, and P. D. Brown, 2005: Atmospheric radiative transfer modeling: A summary of the AER codes. J. Quant. Spectrosc. Radiat. Transfer, 91, 233244, https://doi.org/10.1016/j.jqsrt.2004.05.058.

Codron, F., 2007: Relations between annular modes and the mean state: Southern Hemisphere winter. J. Atmos. Sci., 64, 33283339, https://doi.org/10.1175/JAS4012.1.

Collins, M., and Coauthors, 2013: Long-term climate change: Projections, commitments and irreversibility. Climate Change 2013: The Physical Science Basis, T. F. Stocker et al., Eds., Cambridge University Press, 1029-1136.

Dee, D. P., S. M. Uppala, A. J. Simmons, P. Berrisford, P. Poli, and S. Kobayashi, 2011: The ERA-Interim reanalysis: Configuration and performance of the data assimilation system. Quart. J. Roy. Meteor. Soc., 137, 553-597, https://doi.org/10.1002/qj.828.

Duchon, C. E., 1979: Lanczos filtering in one and two dimensions. J. Appl. Meteor., 18, 1016-1022, https://doi.org/10.1175/15200450(1979)018<1016:LFIOAT > 2.0.CO;2.

Edmon, H. J., B. J. Hoskins, and M. E. McIntyre, 1980: Eliassen-Palm cross sections for the troposphere. J. Atmos. Sci., 37, 2600-2616, http://doi.org/10.1175/1520-0469(1980)037\%3C2600:EPCSFT\% 3E2.0.CO;2.

Egger, J., 1991: On the mean atmospheric circulation over Antarctica. Geophys. Astrophys. Fluid Dyn., 58, 75-90, https:// doi.org/10.1080/03091929108227332.

__ , and K. Fraedrich, 1987: Topographic Rossby waves over Antarctica. Tellus, 39A, 110-115, https://doi.org/10.1111/ j.1600-0870.1987.tb00293.x.

England, M., L. Polvani, and L. Sun, 2018: Contrasting the Antarctic and Arctic atmospheric responses to projected sea ice loss in the late twenty-first century. J. Climate, 31, 63536370, https://doi.org/10.1175/JCLI-D-17-0666.1.

Frierson, D. M. W., I. M. Held, and P. Zurita-Gotor, 2006: A grayradiation aquaplanet moist GCM. Part I: Static stability and eddy scale. J. Atmos. Sci., 63, 2548-2566, https://doi.org/10.1175/JAS3753.1.

Grose, M. R., J. S. Risbey, A. F. Moise, S. Osbrough, C. Heady, L. Wilson, and T. Erwin, 2017: Constraints on southern Australian rainfall change based on atmospheric circulation in CMIP5 simulations. J. Climate, 30, 225-242, https://doi.org/ 10.1175/JCLI-D-16-0142.1.

Held, I. M., M. Ting, and H. Wang, 2002: Northern winter stationary waves: Theory and modeling. J. Climate, 15, 2125-2144, https:// doi.org/10.1175/1520-0442(2002)015<2125:NWSWTA >2.0.CO;2. 
Hoskins, B. J., and D. J. Karoly, 1981: The steady linear response of a spherical atmosphere to thermal and orographic forcing. J. Atmos. Sci., 38, 1179-1196, https://doi.org/10.1175/15200469(1981)038<1179:TSLROA > 2.0.CO;2.

_ and T. Ambrizzi, 1993: Rossby wave propagation on a realistic longitudinally varying flow. J. Atmos. Sci., 50, 1661-1671, https:// doi.org/10.1175/1520-0469(1993)050<1661:RWPOAR >2.0.CO;2.

, and K. I. Hodges, 2005: A new perspective on Southern Hemisphere storm tracks. J. Climate, 18, 4108-4129, https:// doi.org/10.1175/JCLI3570.1.

— I. I. James, and G. H. White, 1983: The shape, propagation and mean-flow interaction of large-scale weather systems. J. Atmos. Sci., 40, 1595-1612, http://doi.org/10.1175/15200469(1983)040\%3C1595:TSPAMF\%3E2.0.CO;2.

Inatsu, M., and B. J. Hoskins, 2004: The zonal asymmetry of the Southern Hemisphere winter storm track. J. Climate, 17, 48824892, https://doi.org/10.1175/JCLI-3232.1.

— , and - 2006: The seasonal and wintertime interannual variability of the split jet and the storm-track activity minimum near New Zealand. J. Meteor. Soc. Japan, 84, 433-445, https://doi.org/10.2151/jmsj.84.433.

James, I. N., 1989: The Antarctic drainage flow: Implications for hemispheric flow on the Southern Hemisphere. Antarct. Sci., 1, 279-290, https://doi.org/10.1017/S0954102089000404.

Jucker, M., and E. P. Gerber, 2017: Untangling the annual cycle of the tropical tropopause layer with an idealized moist model. J. Climate, 30, 7339-7358, https://doi.org/10.1175/JCLI-D-170127.1.

Juckes, M. N., I. N. James, and M. Blackburn, 1994: The influence of Antarctica on the momentum budget of the southern extratropics. Quart. J. Roy. Meteor. Soc., 120, 1017-1044, https:// doi.org/10.1002/qj.49712051811.

Justino, F., J. Marengo, F. Kucharski, F. Stordal, J. Machado, and M. Rodrigues, 2014: Influence of Antarctic ice sheet lowering on the Southern Hemisphere climate: Modeling experiments mimicking the mid-Miocene. Climate Dyn., 42, 843-858, https://doi.org/10.1007/s00382-013-1689-9.

Karoly, D. J., and D. G. Vincent, 1998: Meteorology of the Southern Hemisphere. Amer. Meteor. Soc., 410 pp., https://doi.org/ 10.1007/978-1-935704-10-2.

Lachlan-Cope, T. A., W. M. Connolley, and J. Turner, 2001: The role of the non-axisymmetric Antarctic orography in forcing the observed pattern of variability of the Antarctic climate. Geophys. Res. Lett., 28, 4111-4114, https://doi.org/10.1029/ 2001GL013465.

Lee, R. W., 2015: Storm track biases and changes in a warming climate from an extratropical cyclone perspective using CMIP5. Ph.D. thesis, University of Reading, 411 pp.

Li, X., E. P. Gerber, D. M. Holland, and C. Yoo, 2015: A Rossby wave bridge from the tropical Atlantic to west Antarctica. J. Climate, 28, 2256-2273, https://doi.org/10.1175/JCLI-D14-00450.1.

McFarlane, N. A., 1987: The effect of orographically excited gravity wave drag on the general circulation of the lower stratosphere and troposphere. J. Atmos. Sci., 44, 1775-1800, https://doi.org/ 10.1175/1520-0469(1987)044<1775:TEOOEG > 2.0.CO;2.

Mechoso, C. R., 1980: The atmospheric circulation around Antarctica: Linear stability and finite-amplitude interactions with migrating cyclones. J. Atmos. Sci., 37, 2209-2233, http:// doi.org/10.1175/1520-0469(1980)037\%3C2209:TACAAL\% 3E2.0.CO;2.

_ 1981: Topographic influences on the general circulation of the Southern Hemisphere: A numerical experiment. Mon. Wea.
Rev., 109, 2131-2139, http://doi.org/10.1175/1520-0493(1981) 109\%3C2131:TIOTGC\%3E2.0.CO;2.

Nakamura, H., and T. Sampe, 2002: Trapping of synoptic-scale disturbances into the North-Pacific subtropical jet core in midwinter. Geophys. Res. Lett., 29, 1761, https://doi.org/ 10.1029/2002GL015535.

—, and A. Shimpo, 2004: Seasonal variations in the Southern Hemisphere storm tracks and jet streams as revealed in a reanalysis dataset. J. Climate, 17, 1828-1844, https://doi.org/ 10.1175/1520-0442(2004)017<1828:SVITSH >2.0.CO;2.

Ogawa, F., H. Nakamura, K. Nishii, T. Miyasaka, and A. KuwanoYoshida, 2016: Importance of midlatitude oceanic frontal zones for the annular mode variability: Interbasin differences in the southern annular mode signature. J. Climate, 29, 61796199, https://doi.org/10.1175/JCLI-D-15-0885.1.

Ogura, T., and A. Abe-Ouchi, 2001: Influence of the Antarctic Ice Sheet on southern high latitude climate during the Cenozoic: Albedo vs topography effect. Geophys. Res. Lett., 28, 587-590, https://doi.org/10.1029/2000GL011366.

Parish, T. R., and D. H. Bromwich, 2007: Reexamination of the nearsurface airflow over the Antarctic continent and implications on atmospheric circulations at high southern latitudes. Mon. Wea. Rev., 135, 1961-1973, https://doi.org/10.1175/MWR3374.1.

_,- , and R.-Y. Tzeng, 1994: On the role of the Antarctic continent in forcing large-scale circulations in the high southern latitudes. J. Atmos. Sci., 51, 3566-3579, https://doi.org/10.1175/ 1520-0469(1994)051<3566:OTROTA>2.0.CO;2.

Patterson, M., T. Bracegirdle, and T. Woollings, 2019: Southern Hemisphere atmospheric blocking in CMIP5 and future changes in the Australia-New Zealand sector. Geophys. Res. Lett., 46, 9281-9290, https://doi.org/10.1029/2019GL083264.

Polvani, L. M., and P. J. Kushner, 2002: Tropospheric response to stratospheric perturbations in a relatively simple general circulation model. Geophys. Res. Lett., 29, 1114, https://doi.org/ 10.1029/2001GL014284.

Quintanar, A., and C. Mechoso, 1995: Quasi-stationary waves in the Southern Hemisphere. Part II: Generation mechanisms. J. Climate, 8, 2673-2690, https://doi.org/10.1175/15200442(1995)008<2673: QSWITS>2.0.CO;2.

Sampe, T., H. Nakamura, A. Goto, and W. Ohfuchi, 2010: Significance of a midlatitude SST frontal zone in the formation of a storm track and an eddy-driven westerly jet. J. Climate, $\mathbf{2 3}$, 1793-1814, https://doi.org/10.1175/2009JCLI3163.1.

Simmonds, I., and R. Law, 1995: Associations between Antarctic katabatic flow and the upper level winter vortex. Int. J. Climatol., 15, 403-421, https://doi.org/10.1002/joc.3370150405.

Simpkins, G. R., S. McGregor, A. S. Taschetto, L. M. Ciasto, and M. H. England, 2014: Tropical connections to climatic change in the extratropical Southern Hemisphere: The role of Atlantic SST trends. J. Climate, 27, 4923-4936, https:// doi.org/10.1175/JCLI-D-13-00615.1.

Simpson, I. R., T. Shaw, and R. Seager, 2014: A diagnosis of the seasonally and longitudinally varying mid-latitude circulation response to global warming. J. Atmos. Sci., 71, 2489-2515, https://doi.org/10.1175/JAS-D-13-0325.1.

Singh, H. K. A., C. M. Bitz, and D. M. W. Frierson, 2016: The global climate response to lowering surface orography of Antarctica and the importance of atmosphere-ocean coupling. J. Climate, 29, 4137-4153, https://doi.org/10.1175/ JCLI-D-15-0442.1.

Stephens, G. L., D. O'Brien, P. J. Webster, P. Pilewski, S. Kato, and J. L. Li, 2015: The albedo of Earth. Rev. Geophys., 53, 141-163, https://doi.org/10.1002/2014RG000449. 
Takaya, K., and H. Nakamura, 1997: A formulation of a waveactivity flux for stationary Rossby waves on a zonally varying basic flow. Geophys. Res. Lett., 24, 2985-2988, https://doi.org/ 10.1029/97GL03094.

— , and — 2001: A formulation of a phase-independent wave-activity flux for stationary and migratory quasigeostrophic eddies on a zonally varying basic flow. J. Atmos. Sci., 58, 608-627, http://doi.org/10.1175/1520-0469(2001) 058\%3C0608:AFOAPI\%3E2.0.CO;2.

Taylor, K. E., D. Williamson, and F. Zwiers, 2000: The sea surface temperature and sea-ice concentration boundary conditions of AMIP II simulations. PCMDI Rep. 60, 20 pp.

- R. J. Stouffer, and G. A. Meehl, 2012: An overview of CMIP5 and the experiment design. Bull. Amer. Meteor. Soc., 93, 485498, https://doi.org/10.1175/BAMS-D-11-00094.1.

Thomson, S. I., and G. K. Vallis, 2018: Atmospheric response to SST anomalies. Part I: Background-state dependence, teleconnections, and local effects in winter. J. Atmos. Sci., 75, 4107-4124, https://doi.org/10.1175/JAS-D-17-0297.1.

Vallis, G. K., 2017: Atmospheric and Oceanic Fluid Dynamics: Fundamentals and Large-Scale Circulation. 2nd ed. Cambridge University Press, 946 pp., https://doi.org/10.1017/ 9781107588417.

, E. P. Gerber, P. J. Kushner, and B. A. Cash, 2004: A mechanism and simple dynamical model of the North Atlantic
Oscillation and annular modes. J. Atmos. Sci., 61, 264-280, http://doi.org/10.1175/1520-0469(2004)061\%3C0264:AMASDM\% 3E2.0.CO;2.

— modelling of the atmospheres of Earth and other planets at varying levels of complexity. Geosci. Model Dev., 11, 843-859, https://doi.org/10.5194/gmd-11-843-2018.

van Loon, H., J. J. Taljaard, T. Sasamori, J. London, D. V. Hoyt, K. Labitzke, and C. W. Newton, 1972: Meteorology of the Southern Hemisphere. Meteor. Monogr., No. 35, Amer. Meteor. Soc., 263 pp., https://doi.org/10.1007/978-1-935704-33-1.

Walsh, K. J., I. Simmonds, and M. Collier, 2000: Sigma-coordinate calculation of topographically forced baroclinicity around Antarctica. Dyn. Atmos. Oceans, 33 (1), 1-29, https://doi.org/ 10.1016/S0377-0265(00)00054-3.

Wang, H., and M. Ting, 1999: Seasonal cycle of the climatological stationary waves in the NCEP-NCAR reanalysis. J. Atmos. Sci., 56, 3892-3919, https://doi.org/10.1175/1520-0469(1999) 056<3892:SCOTCS $>2.0$. CO;2.

Williams, L. N., S. Lee, and S.-W. Son, 2007: Dynamics of the Southern Hemisphere spiral jet. J. Atmos. Sci., 64, 548-563, https://doi.org/10.1175/JAS3939.1.

Woollings, T., A. Hannachi, and B. Hoskins, 2010: Variability of the North Atlantic eddy-driven jet stream. Quart. J. Roy. Meteor. Soc., 136, 856-868, https://doi.org/10.1002/qj.625. 